\title{
The calcium-binding protein parvalbumin modulates the firing 1 properties of the reticular thalamic nucleus bursting neurons
}

\author{
Lavinia Albéri, ${ }^{1}$ Alessandra Lintas, ${ }^{1,2}$ Robert Kretz, ${ }^{1}$ Beat Schwaller, ${ }^{1}$ and Alessandro E. P. Villa ${ }^{2}$ \\ ${ }^{1}$ Unit of Anatomy, Department of Medicine, University of Fribourg, Fribourg, Switzerland; and ${ }^{2}$ Laboratory of \\ Neuroheuristics, Department of Information Systems, University of Lausanne, Lausanne, Switzerland
}

\begin{abstract}
Albéri L, Lintas A, Kretz R, Schwaller B, Villa AE. The calcium-binding protein parvalbumin modulates the firing 1 properties of the reticular thalamic nucleus bursting neurons. $J$ Neurophysiol 109: 2827-2841, 2013. First published March 13, 2013; doi:10.1152/jn.00375.2012.-The reticular thalamic nucleus (RTN) of the mouse is characterized by an overwhelming majority of GABAergic neurons receiving afferences from both the thalamus and the cerebral cortex and sending projections mainly on thalamocortical neurons. The RTN neurons express high levels of the "slow $\mathrm{Ca}^{2+}$ buffer" parvalbumin (PV) and are characterized by low-threshold $\mathrm{Ca}^{2+}$ currents, $I_{\mathrm{T}}$. We performed extracellular recordings in ketamine/ xylazine anesthetized mice in the rostromedial portion of the RTN. In the RTN of wild-type and PV knockout (PVKO) mice we distinguished four types of neurons characterized on the basis of their firing pattern: irregular firing (type I), medium bursting (type II), long bursting (type III), and tonically firing (type IV). Compared with wild-type mice, we observed in the PVKOs the medium bursting (type II) more frequently than the long bursting type and longer interspike intervals within the burst without affecting the number of spikes. This suggests that PV may affect the firing properties of RTN neurons via a mechanism associated with the kinetics of burst discharges. $\mathrm{Ca}_{\mathrm{v}} 3.2$ channels, which mediate the $I_{\mathrm{T}}$ currents, were more localized to the somatic plasma membrane of RTN neurons in PVKO mice, whereas $\mathrm{Ca}_{\mathrm{v}} 3.3$ expression was similar in both genotypes. The immunoelectron microscopy analysis showed that $\mathrm{Ca}_{\mathrm{v}} 3.2$ channels were localized at active axosomatic synapses, thus suggesting that the differential localization of $\mathrm{Ca}_{\mathrm{v}} 3.2$ in the PVKOs may affect bursting dynamics. Cross-correlation analysis of simultaneously recorded neurons from the same electrode tip showed that about one-third of the cell pairs tended to fire synchronously in both genotypes, independent of PV expression. In summary, PV deficiency does not affect the functional connectivity between RTN neurons but affects the distribution of $\mathrm{Ca}_{\mathrm{v}} 3.2$ channels and the dynamics of burst discharges of RTN cells, which in turn regulate the activity in the thalamocortical circuit.
\end{abstract}

parvalbumin; reticular thalamic nucleus; firing properties

THE RETICULAR THALAMIC NUCLEUS (RTN) represents a unique gateway in filtering and sorting sensory information that passes through the thalamocortical and corticothalamic axis (Jones 1975; Yingling and Skinner 1976; Guillery et al. 1998). On the basis of its interconnectivity, the RTN is thought to play an important role in attention and information processing (Crick 1984; Steriade et al. 1987; Villa et al. 1999; Jones 2009; Halassa et al. 2011). More recently attention deficit disorder and schizophrenia have also been linked to dysfunction of the RTN (Behrendt 2006; DeLorey et al. 2011). In all mammals studied so far, the RTN appears as a thin sheath-like structure

Address for reprint requests and other correspondence: A. E. Villa, Laboratory of Neuroheuristics, Univ. of Lausanne, UNIL Dorigny-Internef 138.1, CH-1015 Lausanne, Switzerland (e-mail: Alessandro.Villa@unil.ch). of neurons, topographically located between the cortex and dorsal thalamus, which is innervated by excitatory collaterals of the thalamocortical and corticothalamic pathways (Jones 1975). It also receives cholinergic and serotonergic innervation from the brainstem (Jones 1991). In return the RTN, which is rich in parvalbumin (PV)-positive neurons, sends GABAmediated inhibitory projections to the thalamic relay nuclei (Jones and Hendry 1989).

$\mathrm{PV}$ is a $\mathrm{Ca}^{2+}$-buffer protein that is highly expressed in RTN neurons (Celio 1990). PV is characterized by a slow-onset $\mathrm{Ca}^{2+}$ binding that generally does not affect the initial amplitude of $\mathrm{Ca}^{2+}$ transients but then accelerates the decay phase, thus often converting a monoexponential intracellular $\mathrm{Ca}^{2+}$ concentration $\left(\left[\mathrm{Ca}^{2+}\right]_{\mathrm{i}}\right)$ decay into a biexponential one (Collin et al. 2005; Lee et al. 2000). The acceleration of the early phase of $\left[\mathrm{Ca}^{2+}\right]_{\mathrm{i}}$ decay associated with PV activity limits or slows down the buildup of residual $\left[\mathrm{Ca}^{2+}\right]_{\mathrm{i}}$ in presynaptic terminals, thus affecting short-term plasticity (Caillard et al. 2000; Vreugdenhil et al. 2003). The presence of low-voltage-activated (LVA) $\mathrm{Ca}_{\mathrm{v}} 3 \mathrm{Ca}^{2+}$ channels allows transient low-threshold $\mathrm{Ca}^{2+}$ currents $\left(I_{\mathrm{T}}\right)$ to trigger low-threshold spikes (LTS) underlying the burst firing (Huguenard and Prince 1992; PerezReyes 2003). Recently, it has been reported that these $I_{\mathrm{T}}$ currents are present both at the soma and distal dendrites (Crandall et al. 2010) and that they are tightly regulated through the competitive interaction with the $\mathrm{Ca}^{2+}$-dependent small-conductance $\mathrm{K}^{+}$channels (SK) and the sarco(endo)plasmic reticulum $\mathrm{Ca}^{2+}$-ATPase (SERCA) (Coulon et al. 2009; Cueni et al. 2008). All of the above mentioned proteins, including PV, are important in maintaining $\mathrm{Ca}^{2+}$ homeostasis and conferring phenotypic stability (Schwaller 2012). There is ample evidence that mutations in (or ablation of) $\mathrm{Ca}^{2+}$ signaling components in neurons lead to changes in the remaining ones with respect to expression levels, localization, and even change in cell morphology, e.g., of organelles implicated in $\mathrm{Ca}^{2+}$ signaling (Schwaller 2012).

Most RTN neurons fire with a characteristic bursting discharge pattern, but a subpopulation of RTN neurons has been reported to fire tonically (Contreras et al. 1992; Lee et al. 2007; Villa 1990). These electrophysiological observations are in agreement with the morphological observation of the presence of several neuronal subtypes in the RTN (Clemence and Mitrofanis 1992; Houser et al. 1980; Jones 1975; Lubke 1993; Scheibel and Scheibel 1966; Yen et al. 1985). Synchronous activity of RTN cells is likely to exert a powerful GABAmediated inhibition onto the dorsal thalamus and provoke spike wave discharges that can resonate and result in oscillations (Steriade et al. 1985, 1987). Thus, the physiological properties 
of RTN neurons have been recognized to play a key role in spindle rhythmicity (Destexhe et al. 1993; Wang and Rinzel 1993). Our former study reported that loss of PV induced frequency-dependent increases in GABAergic release (increased short-term facilitation, Caillard et al. 2000; Vreugdenhil et al. 2003). At the network level PV deficiency was found to enhance susceptibility to epileptic seizure (Schwaller et al. 2004), thus supporting the hypothesis of PV being involved in the precise regulation of $\mathrm{Ca}^{2+}$ signaling.

The aim of the present work is to determine more precisely how the activity of RTN neurons is affected by the changes in intracellular $\mathrm{Ca}^{2+}$ dynamics provoked by the deficiency of PV. We investigate in vivo the firing properties of RTN neurons in anesthetized wild-type (WT) and PV knockout (PVKO) mice by means of extracellular recordings. The analysis of the activity of pairs of RTN neurons recorded simultaneously allows the study of the functional interactions and addresses whether synchronous activity between RTN neurons is modified in PVKO mice. Since the onset of PV expression is strongly correlated with the maturation of neuronal circuits (e.g., in the cerebellum, Collin et al. 2005), it is possible that the absence of PV might also entail modifications in the connectivity of the "PV-neurons" in the RTN network. Based on the recent finding suggesting that the proportion between distal and proximal $\mathrm{LVA} \mathrm{Ca}^{2+}$ channels expression is critical for the generation and propagation of bursts in RTN cells (Crandall et al. 2010; Coulon et al. 2009), we performed an immunohistochemical analysis using a reporter mouse line expressing enhanced green fluorescent protein (EGFP) under the control of the PV promoter (Meyer et al. 2002) and immunoelectron microscopy of the RTN to determine the localization of $\mathrm{Ca}_{\mathrm{v}} 3.2$ and $\mathrm{Ca}_{\mathrm{v}} 3.3$ channels. We show that in PVKO medium bursting RTN units were prevailing and that there was a general prolongation of the burst duration. An increase in somatic localization of $\mathrm{Ca}_{\mathrm{v}} 3.2$ channels in the RTN of PVKO mice hints that this differential channel localization may underlie the different burst dynamic observed in the PVKO mice. However, no significant effect on the functional connectivity between RTN neurons could be observed.

\section{MATERIALS AND METHODS}

\section{Mice}

PV-deficient (PVKO) mice were originally generated on a mixed C57Bl/6J $\times 129 /$ OlaHsd genetic background (Schwaller et al. 1999) and backcrossed to $\mathrm{C} 57 \mathrm{~B} 1 / 6 \mathrm{~J}$ for 10 generations and are thus considered to be congenic to C57B1/6J (Moreno et al. 2012); C57B1/6J mice thus served as the control WT mice. All animals, including WT ones, were genotyped by PCR. Mice used for the experiments were between 3 and 5 mo old and weighed 25-30 g. We aimed to minimize the number of mice and all experiments were performed with the permission of the local animal care committee (Canton of Fribourg, Switzerland) and according to the present Swiss law and the European Communities Council Directive of 24 November 1986 (86/609/EEC). Animals were housed in groups of three to five individuals on a 12:12-h light-dark cycle (light onset at $7 \mathrm{AM}$ ) with free access to food and water.

\section{Surgery and Extracellular In Vivo Recordings}

The mice (7 WT and 7 PVKO, 25-30 g of weight) were deeply anesthetized with an intraperitoneal injection of a mixture of ketamine (stock $100 \mathrm{mg} / \mathrm{ml}$ Ketanarkon; Streuli) and xylazine (stock $20 \mathrm{mg} / \mathrm{ml}$ xylazine; Streuli) at concentrations of $100 \mathrm{mg} / \mathrm{kg}$ and $10 \mathrm{mg} / \mathrm{kg}$, respectively, diluted in saline $(0.9 \% \mathrm{NaCl}$; B. Braun) such that the injected volume was $4 \mu \mathrm{l} / \mathrm{g}$. The withdrawal reflex was regularly checked, and heart rate was monitored to detect any change in the depth of anesthesia. Supplementary doses of $2 \mu \mathrm{l} / \mathrm{g}$ ketamine/xylazine mixture were injected every hour to keep a steady anesthetic state. The animals were mounted in a stereotaxic apparatus (Stoelting). The body temperature was maintained using a heating pad set to $37.5^{\circ} \mathrm{C}$. Single glass-coated, platinum and gold-plated tungsten electrodes with impedance between 1-2 M $\Omega$ were used for all recordings. The electrodes were advanced at the bregma using a motorized Stereodrive stereotaxic apparatus (Neurostar). Anterior-posterior and medial-lateral coordinates corresponding to the rostral-medial RTN were $0.65-1.05 \mathrm{~mm}$ from bregma according to the Allen mouse brain atlas (http://mouse. brain-map.org/). After local opening of the skull, the electrodes were driven to the surface of the brain using a micromanipulator (Kopf). The electrodes were then progressively advanced to the depth of the RTN. Signals from the electrodes were amplified, filtered (400-2,000 $\mathrm{Hz}$ ), visualized on an oscilloscope, digitally recorded in WAV format $(44,100-\mathrm{Hz}$ sampling rate, $16 \mathrm{bit})$, and stored for post hoc analysis. The files were analyzed offline using a spike-sorting program (Aksenova et al. 2003; Asai et al. 2005). Up to three cells were detected from a single electrode. The spike trains were digitally stored for time series analysis.

\section{Histological and Immunohistochemical Examinations}

Following the recording session (3-4 h), electrolytic lesions using three pulses of $5 \mu \mathrm{A}$ for $7 \mathrm{~s}$ at intervals of $5 \mathrm{~s}$ were induced at the bottom of the electrode track and at the location where the recording was started when the electrode was retracted. Mice were given a sublethal dose of $8 \mu \mathrm{l} / \mathrm{g}$ ketamine/xylazine and perfused transcardially with $50 \mathrm{ml}$ of $0.9 \% \mathrm{NaCl}$, followed by $4 \%$ paraformaldehyde in $0.1 \mathrm{M}$ phosphate buffer. Brains were removed after perfusion and cut at $50-\mu \mathrm{m}$ thickness with a vibratome (Leica). Sections were mounted on two parallel slide series for cresyl violet staining and staining for PV and specific lectins, which are part of the perineuronal nets around PV-expressing neurons (Celio et al. 1998). Cresyl violet staining was used for the reconstruction of the electrode tracks. The immunohistochemistry was carried out using the rabbit anti-PV, PV4064 antiserum (1:5,000; Swant, Bellinzona, Switzerland), and the labeling of lectins was carried out using a Texas Red directly conjugated Wisteria Floribunda agglutinin (WFA; 1:100; Y-Laboratories). PV was then visualized using a secondary antibody Alexa 488 donkey anti-rabbit antibody (Invitrogen). DAPI (Roche) was applied at the end to label cell nuclei (double-stranded DNA staining; Fig. 1). After track reconstruction, the recording sites were mapped to the closest coronal section of the Allen mouse brain atlas. To restrict the analysis of the LVA $\mathrm{Ca}_{\mathrm{v}} 3$ channels to PV-positive neurons of the RTN, we took advantage of the PV-EGFP mouse line (Meyer et al. 2002). To label the EGFP-positive cells we used either the goat anti-EGFP (Rockland) in combination with the rabbit anti-Ca 3.2 (Novus Biologicals, Cambridge, UK) (Toyota et al. 1999) or rabbit anti-EGFP (Invitrogen, Carlsbad, CA) in combination with goat anti-Ca 3.3 (Santa Cruz Biotechnology, Santa Cruz, CA) (Liu et al. 2011) on vibratome sections of WT/PV-EGFP and PVKO/PV-EGFP mice.

The secondary antibodies were, respectively, Alexa 488 donkey antigoat (Invitrogen) and Cy3 donkey anti-rabbit (Jackson Immunoresearch) or Alexa 488 donkey anti-rabbit (Invitrogen) and Cy3 donkey anti-goat (Jackson Immunoresearch). The images were acquired with a TCS SP5 II confocal microscope (Leica) by $0.4-\mu \mathrm{m}$ optical slicing of $6-\mu \mathrm{m}$ slice depth. We performed the analysis offline using the integrated density quantification software of the Leica LAS Lite application. The study was done blind. We restricted our study to regions of interest (ROIs) either on the soma of the EGFP-positive cells or on the EGFP-positive processes. Ten ROIs were sampled per RTN on all optical slices from each section. At least three consecutive sections were analyzed per animal. Expression 
A

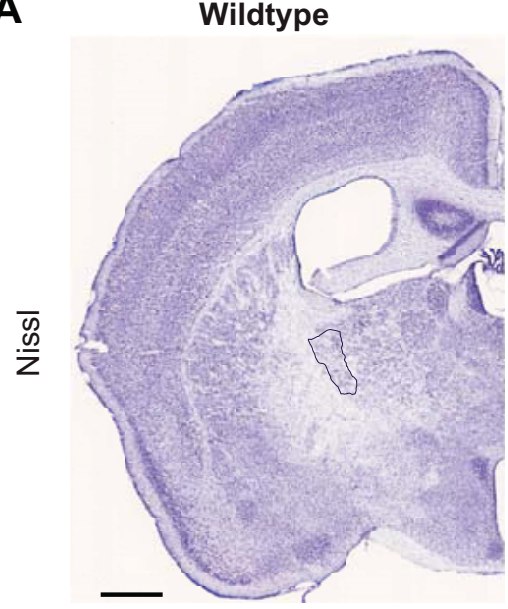

B

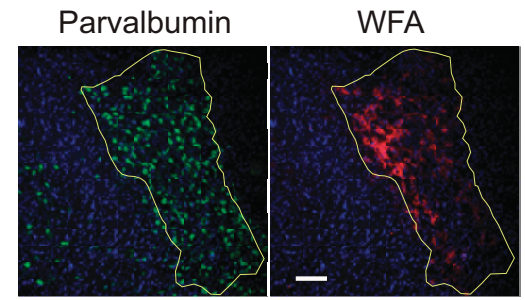

C

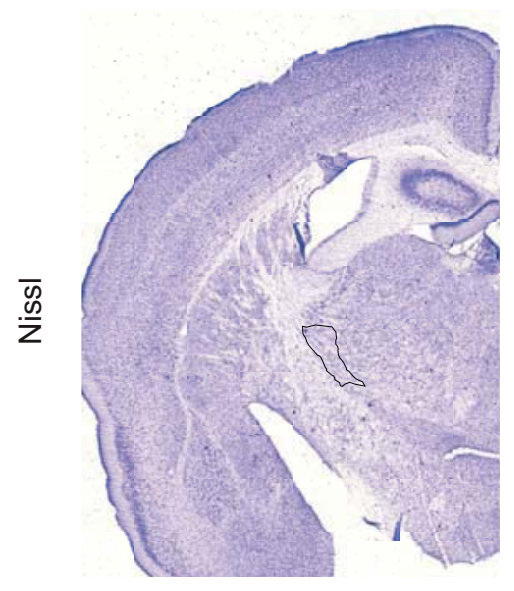

D

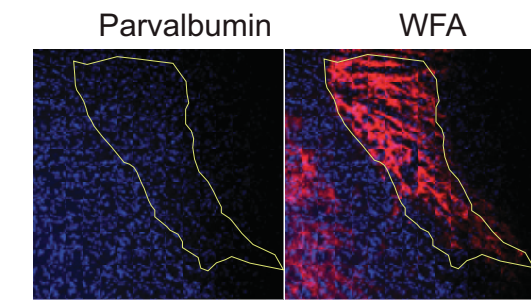

Fig. 1. Histology, immunohistochemistry, and example of recording track reconstruction. Cresyl violet staining of coronal sections of wild-type $(A)$ and parvalbumin knockout $(\mathrm{PVKO} ; C)$ animals at approximately stereotaxic coordinates interaural (IA): -0.95 of the Allen mouse brain atlas. A thin blue line delineates the reticular thalamic nucleus (RTN) corresponding to the Wisteria Floribunda agglutinin (WFA)-positive areas shown at bottom. $B$ and $D$ : double immunofluorescence staining for parvalbumin and WFA indicates the presence of RTN interneurons also in the absence of PV. A thin yellow line delineates the outline of the WFA-positive area. E: Nissl staining showing 2 reference lesion sites $(*)$ along 1 experimental electrode penetration (E21). F: coronal sections (IA: -0.75 ; IA: -0.88 ) from the Allen Brain Atlas corresponding to the Nissl section of $E$ and reconstructed track of penetration E21 with the estimated locations of the recording sites within RTN. Scale bars $=1,000 \mu \mathrm{m}$ in $A$ and $50 \mu \mathrm{m}$ in $B$.
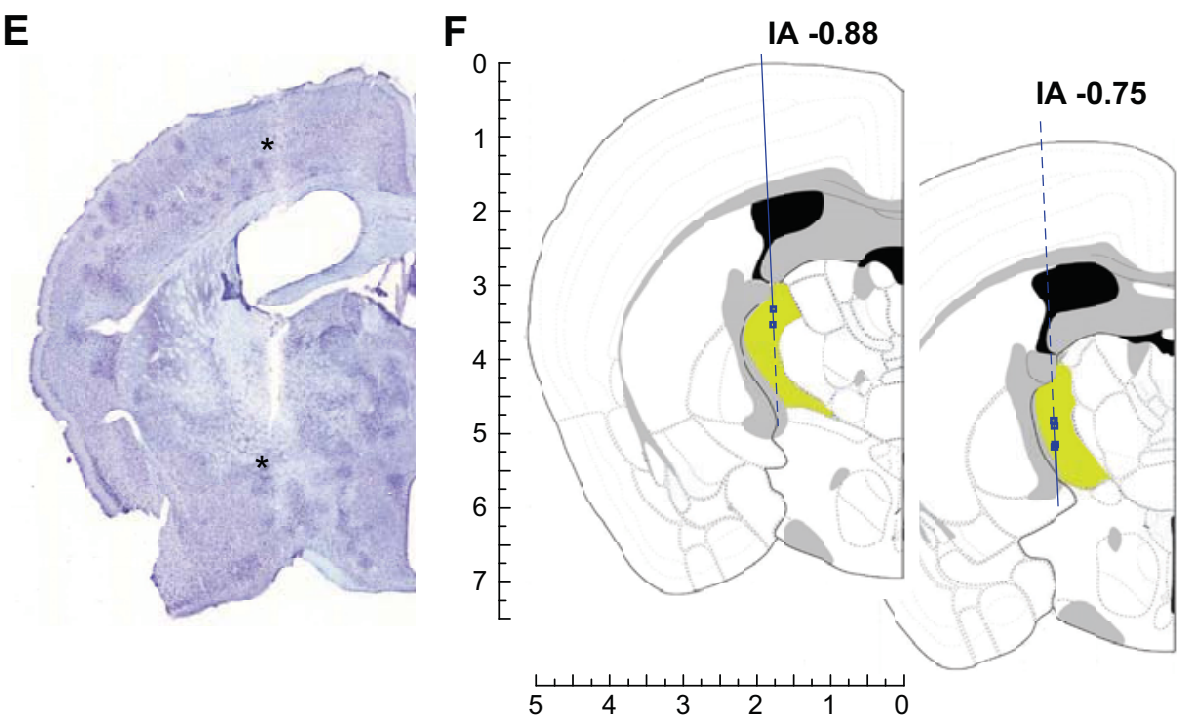

of $\mathrm{Ca}_{\mathrm{v}} 3$ channels was quantified as pixel per micrometers squared on each optical plane and then averaged for comparison. EGFP expression was also quantified to control for variability in the staining.

\section{Preembedding Immunoelectron Microscopy}

Mice were anesthetized and perfused transcardially with $50 \mathrm{ml}$ of $0.9 \% \mathrm{NaCl}$, followed by $4 \%$ paraformalde-hyde in $0.1 \mathrm{M}$ phosphate buffer. Brains were removed after perfusion and cut at 50- $\mu \mathrm{m}$ thickness with a vibratome (Leica, Germany). Sections were collected in a 12-well plate containing $0.05 \mathrm{M}$ Tris·HCl-buffered saline (TBS; $\mathrm{pH}$ 7.4). The sections were incubated with a blocking solution containing $10 \%$ (vol/ vol) normal goat serum in TBS for 30 min to block nonspecific immunoreactivity. Thereafter, sections were incubated with the primary antibody $\mathrm{Ca}_{\mathrm{v}} 3.2$ (Novus Biologicals, Cambridge, UK), in blocking solution overnight for 4 days. The signal was then amplified using biotinylated secondary antibody, avidin horseradish peroxidase (ABC kit; Vector, Burlingame, CA). Sections were then incubated at room temperature with $0.05 \mathrm{M}$ Tris $\cdot \mathrm{HCl}$ buffer $(\mathrm{pH}$ 7.6) containing $0.05 \%$ diaminobenzidine (Roche) and $0.03 \% \mathrm{H}_{2} \mathrm{O}_{2}$. Once the brown precipitate was clearly visible in the RTN, the sections were washed two times with TBS and postfixed with $2 \%$ glutaraldehyde in cacodylate buffer and kept in the solution overnight. The next day they were incubated in $0.1 \mathrm{M}$ phosphate buffer (pH 7.4) containing 1\% (wt/vol) OsO4 for $1 \mathrm{~h}$. Subsequently, the sections were counterstained with $1 \%(\mathrm{wt} / \mathrm{vol})$ uranyl acetate in $70 \%$ ethanol for $1 \mathrm{~h}$. After dehydration, the sections were mounted on silicon-coated glass slides and flat embedded in epoxy resin (Durcupan; Fluka). Once the resin had polymerized, the flat-embedded sections were examined under a dissection microscope. Two RTN regions were selected from each brain and cut out with a sharp razor blade. The samples of the selected tissue pieces were cut into 50- to 70-nm-thick ultrathin sections on an ultrami- 
crotome (Ultratome, Reichert-Jung). The ultrathin sections were mounted onto single-slot grids (4-5 sections per grid) coated with piloform membrane (Agar Scientific, Stansted, UK) and examined with an electron microscope (CM100; Philips, Eindhoven, The Netherlands).

\section{Statistical Analysis}

Spike trains were analyzed by time series renewal density plots (Abeles 1982). For each histogram, the 99\% confidence limits were calculated, assuming that spikes occurred following a Poisson distribution. The average burst size (ABS) and the bursting index (BI) were calculated as indicated before (Villa 1990). The Fano factor may be used to characterize the variability of the spike train, and it is equal to 1 for the data generated according to Poisson processes (Sacerdote et al. 2006). The firing properties of RTN neurons of both groups of mice were compared by Wilcoxon rank sum test. Two-way ANOVA was used to assess whether the genotype had any effect on the distribution of the firing types. Leave-one-out cross-validation was utilized to assess significance and the generalized error. Bayesian inference was used to calculate the predicted values for pairing combination. Spearman's rank correlation was applied to assess any significant correlation between expected and observed values. Statistical analyses (Teetor 2011; R Core Team 2012) were performed with the R Project for Statistical Computing (http://www.r-project.org/).

\section{RESULTS}

\section{Electrophysiological Recordings}

In the absence of any specific stimulation, background activity under steady-state anesthesia was collected from
231 recording sites, 132 for $7 \mathrm{WT}$, and 99 for 7 PVKO mice. The recording tracks, crossing through the RTN, were verified with histological staining and immunofluorescence for PV and WFA staining. The reactivity for WFA, the perineuronal net marker around GABAergic interneurons (Celio et al. 1998), confirmed that GABAergic neurons in the RTN are still viable (Schwaller et al. 2004) despite the lack of PV (Fig. 1). After electrode track reconstruction, we could confirm that 67 recording sites along 13 tracks for WT and 51 recording sites along 10 tracks for PVKO mice were located in the RTN (Fig. 2).

Distinct waveforms recorded from the same location were considered to be generated by distinct single units. In $\sim 85 \%$ of either group of mice we detected more than one single unit at one recording site in the RTN after waveform-based spikesorting discrimination. In only one case in the WT and one case in the PVKO we could discriminate three distinct single units at the same recording site. Overall we analyzed the background activity of 216 neurons, 113 WT from 67 recording sites and 103 PVKO from 51 recording sites. The duration of a recording lasted between 229 and $300 \mathrm{~s}$ (on average $284 \mathrm{~s}$ ). The firing rates varied between 0.1 and 14.4 spikes/s. We discarded 37 neurons out of 216 from further analysis either because the spike train contained an insufficient number of events for a reliable statistics $(n=16$ in WT and $n=17$ in PVKO with firing rates below 1 spike/s) or because of an oscillatory pattern in the autocorrelation $(n=4$ in WT, found only at the end of one experiment at the bottom of the electrode track in the
Fig. 2. Superimposed coronal sections, made from the stereotaxic Allen mouse brain atlas at the indicated distances (in $\mathrm{mM}$ ) from the bregma showing the histological reconstruction of the electrode penetrations in the RTN of wild-type (WT) and PVKO mice. Electrode tracks are identified by a letter corresponding to the experimental animal. Electrodes with more than one penetration point are indicated by a second number in the code (i.e., S11 and S12). Some electrodes are present in 2 consecutive planes due to the position of the electrode (i.e., D21). Squares along the tracks show the recording sites. Putative location of RTN is highlighted in yellow.

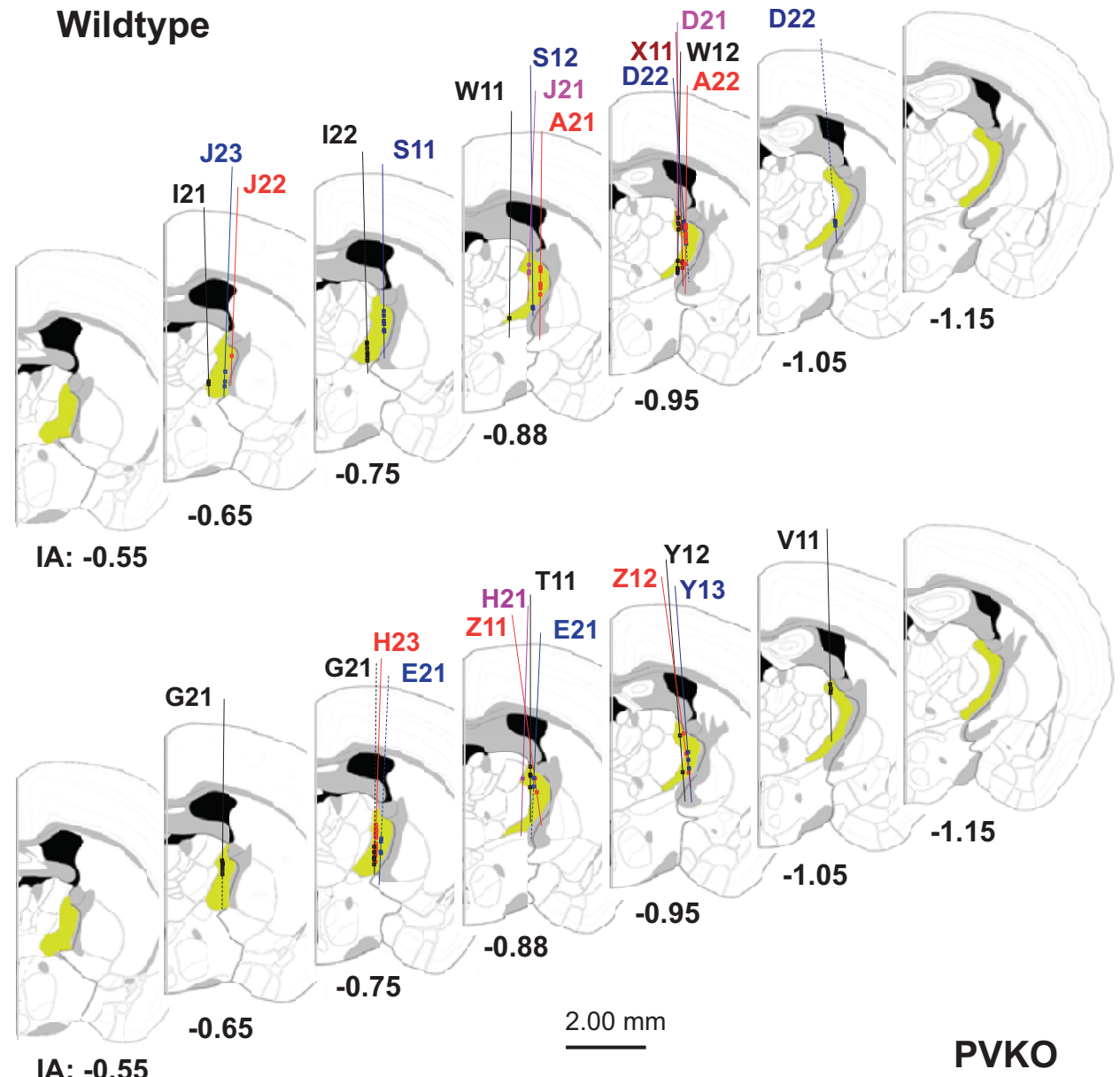

IA: -0.55 
RTN). The whole data sample of RTN neurons was formed by 179 spike trains, 93 in WT and 86 in PVKO mice.

\section{Properties of RTN Neurons in WT and PVKO Mice}

The spike train analysis and the visual inspection of the dot raster plots revealed firing patterns ranging from irregular and tonic activity to long lasting bursts in both genotypes. From the 179 overall sample of cells we observed that 31 were characterized by autorenewal density curves, thus indicating a nonbursting firing pattern with tonically isolated spikes following a Poisson statistical distribution. According to the analysis of the cat RTN neurons (Villa 1990), this firing mode was labeled type IV.

The remaining 148 firing patterns were initially characterized by the analysis of their ABS. The histogram of the ABS shows a multimodal distribution, with modes at 2.5, 3.5, and 7 spikes (Fig. 3A). The presence of three modes suggested that the sample is formed by at least three subsamples that correspond to three different firing modes. According to Villa (1990) the three firing modes are labeled type I-III, with type III being characterized by the largest bursts. The criterion to define the threshold values to apply for an objective definition of the bursting type was based on the fit of the overall distribution of ABS by three gamma distributions. These gamma distributions were characterized by the shape and rate parameters equal to 17.2 and $7.8,14.0$ and 4.9 , and 6.2 and 0.9 for type I, type II, and type III, respectively (Fig. 3C). The intersection of the descending slope of the gamma fit of type I with the ascending slope of the gamma fit of type II corresponded to $\mathrm{ABS}=2.6$ spikes. The intersection of the descending slope of the gamma fit of type II with the ascending slope of the gamma fit of type III corresponded to $\mathrm{ABS}=4.1$ spikes. These values were used to select the

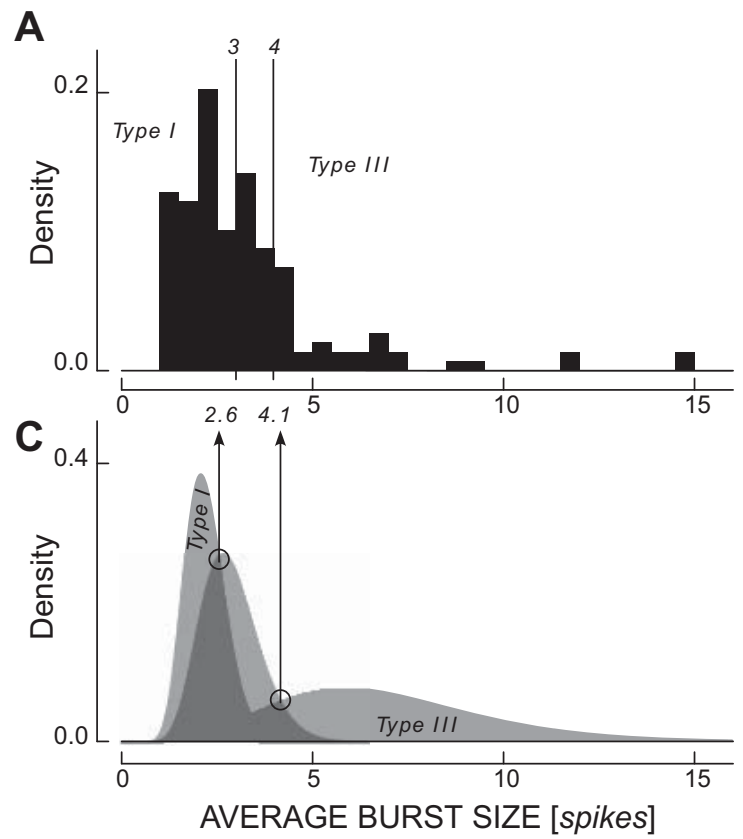

exclusion values of ABS equal to 3 and 4 for type I and type III, respectively.

A similar analysis was performed on the whole sample of type I-III cells for the BI, which depends on the firing rate and the number of spikes in a burst. Hence, BI is negatively correlated to the tendency of a neuron to fire in bursts. The histogram of the BI shows a multimodal distribution, with modes centered at 3 and $11 \mathrm{~Hz}$, with a skewed distribution between the two modes (Fig. 3B). Based on the assumption that this sample was also formed by a mixture of three populations we performed a fit of the overall distribution of BI by three gamma distributions. The shape and rate parameters of the BI gamma distributions were equal to 3.9 and $0.3,7.7$ and 2.1, and 6.3 and 3.8 for type I, type II, and type III, respectively (Fig. $3 D)$. The intersections between the gamma distributions corresponded to $\mathrm{BI}=2.5$ and $\mathrm{BI}=6.0 \mathrm{~Hz}$.

In summary, types I, II and III were defined by an increasing bursting activity and type IV by firing no burst spontaneously (Table 1). The criteria previously used for cat RTN (Villa 1990) were adapted as follows.

Type I. This type of neuron fired single spikes with some tendency to fire in very short burst (Fig. 4A). The neurons that had less than three spikes in a burst (ABS) and a BI $\geq 6 \mathrm{~Hz}$ were classified as type I. The Fano factor was equal to 1.9 on average $( \pm 0.1 \mathrm{SE})$ for either group of mice.

Type II. This type of neuron fired medium bursts consisting of approximately spikes per burst (Fig. 4B). They were classified on the basis of the nontype I-III criteria (Villa 1990) and were characterized by a Fano factor equal to 2.3 on average $( \pm 0.1, \mathrm{SE})$.

Type III. This type of neuron fired larger bursts (Fig. 4C). They were characterized by an ABS $>4$ and a $\mathrm{BI}<3$ (Table $1)$ and a Fano factor equal to 3.2 on average $( \pm 0.3 \mathrm{SE})$.

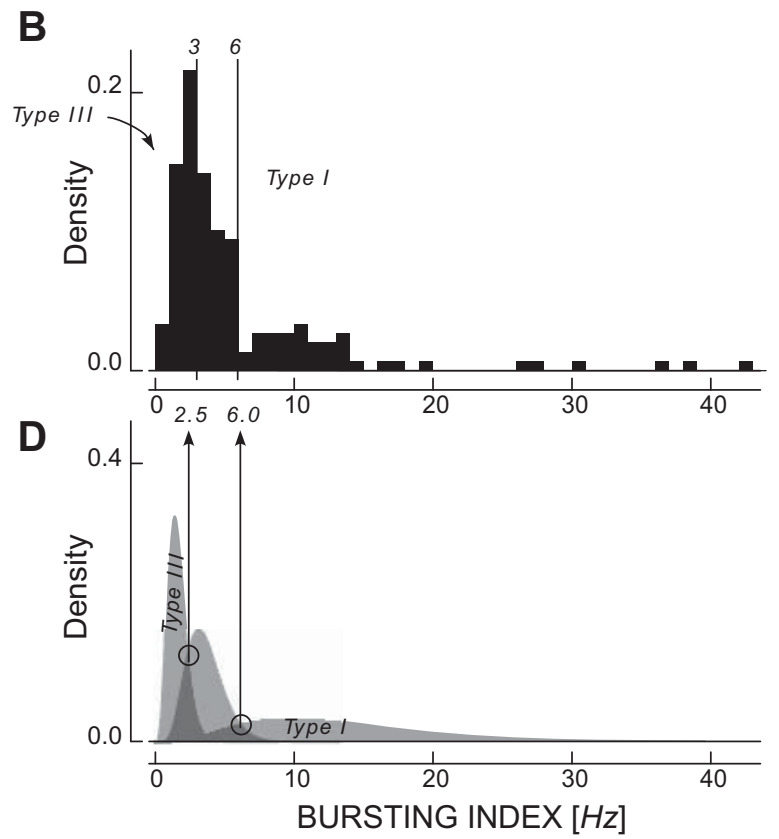

Fig. 3. Relative frequency (density) of the distribution of the average burst size (ABS) and bursting index (BI) for the overall sample formed by 148 cells recorded in the RTN of WT and PVKO mice. Histogram bin size for ABS $(A)$ is 0.5 spikes and for BI $(B)$ is $1 \mathrm{~Hz}$. The fit of the multimodal distributions by a mixture of 3 gamma distributions for $\mathrm{ABS}(C)$ and $\mathrm{BI}(D)$ shows the points of intersection that are used to define the values of the criteria necessary to define the firing mode. Type I is the least bursty, and type III the most bursty firing mode. 
Table 1. Spontaneous activity parameters of the RTN units

\begin{tabular}{|c|c|c|c|c|c|c|}
\hline Type/Genotype & $N$ & $\begin{array}{l}\text { Firing Rate, } \\
\text { spikes/s }\end{array}$ & $\begin{array}{l}\text { Average Burst } \\
\text { Duration, ms }\end{array}$ & $\begin{array}{l}\text { Average Burst Size, } \\
\text { spikes }\end{array}$ & $\begin{array}{l}\text { Bursting Index, } \\
\text { Hz }\end{array}$ & $\begin{array}{c}\text { Intraburst } \\
\text { Frequency, } \mathrm{Hz}\end{array}$ \\
\hline \multicolumn{7}{|l|}{ I } \\
\hline WT & $22(24 \%)$ & $3.6(4.2 \pm 0.5)$ & $50(54 \pm 6)$ & $1.5(1.7 \pm 0.1)$ & $11.0(13.9 \pm 1.7)$ & $33(37 \pm 5)$ \\
\hline PVKO & $16(19 \%)$ & $4.4(4.4 \pm 0.4)$ & $63(73 \pm 9)$ & $1.7(1.7 \pm 0.1)$ & $11.8(15.6 \pm 2.6)$ & $27(26 \pm 2)$ \\
\hline \multicolumn{7}{|l|}{ II } \\
\hline WT & $34(37 \%)$ & $2.4(3.2 \pm 0.3)$ & $45(44 \pm 3)$ & $3.0(3.0 \pm 0.2)$ & $3.1(3.1 \pm 0.2)$ & $72(83 \pm 7)$ \\
\hline PVKO & $48(56 \%)$ & $3.1(3.8 \pm 0.3)$ & $70(77 \pm 6)$ & $2.9(2.9 \pm 0.1)$ & $4.2(4.0 \pm 0.2)$ & $41(50 \pm 4)$ \\
\hline \multicolumn{7}{|l|}{ III } \\
\hline WT & $19(20 \%)$ & $3.8(4.0 \pm 0.4)$ & $50(62 \pm 7)$ & $5.6(7.1 \pm 0.8)$ & $1.4(1.5 \pm 0.1)$ & $146(136 \pm 14)$ \\
\hline PVKO & $9(10 \%)$ & $4.1(5.3 \pm 0.9)$ & $75(82 \pm 13)$ & $6.4(6.1 \pm 0.6)$ & $2.1(2.0 \pm 0.2)$ & $83(81 \pm 6)$ \\
\hline \multicolumn{7}{|l|}{ IV } \\
\hline WT & $18(19 \%)$ & $2.7(3.5 \pm 0.8)$ & $5^{*}(6 \pm 1)$ & - & - & - \\
\hline PVKO & $13(15 \%)$ & $3.2(3.4 \pm 0.6)$ & $5 *(5 \pm 0)$ & - & - & - \\
\hline \multicolumn{7}{|l|}{ Total } \\
\hline WT & $93(100 \%)$ & $3.1(3.7 \pm 0.2)$ & - & - & - & - \\
\hline PVKO & $86(100 \%)$ & $3.6(4.0 \pm 0.2)$ & - & - & - & - \\
\hline
\end{tabular}

Spontaneous activity parameters of the reticular thalamic nucleus (RTN) units are grouped by class of bursting (median, means \pm SE) in normal [wild-type (WT)] and parvalbumin-deficient (PVKO) mice. For type IV, the average burst duration corresponds to the refractory period. Statistics are described in the text.

Type IV. This type of nonbursting neuron fired tonically isolated spikes with a refractory period of $5 \mathrm{~ms}$ (Fig. 4D). This firing dynamics is close to a random renewal process and was characterized by an average Fano factor equal to $1.2( \pm 0.1 \mathrm{SE})$.

The firing rates were not significantly different between the four firing types, but we observed a tendency of higher rates of discharges in the PVKO vs. WT (Wilcoxon rank sum test, $\mathrm{W}=3,474$, ns). The average burst duration was very similar between neuronal types within the same genotype. However, in the absence of PV there was a consistent and significant increase in the burst duration in all neuronal types (Table 1) compared with WT (Wilcoxon rank sum test, $\mathrm{W}=3783,2$ $P<0.001)$.

The significance of the overall distribution of the RTN firing types was assessed by a two-way ANOVA. The first factor (4 levels) is the firing type (i.e., types I, II, III, and IV), with repeated measures $(n=7)$ obtained by leave-one-out cross-
Fig. 4. Representative examples of the 4 firing patterns observed in the RTN. $A-D$ show the oscilloscope traces of the extracellularly recorded single unit, the autocorrelogram (autorenewal density histogram) with the firing rate (spikes/s) plotted against the lag (ms) and a raster plot corresponding to $20 \mathrm{~s}$ of activity. Curves are smoothed by a Gaussian bin of $5 \mathrm{~ms}$. Dotted line indicates the upper limit of confidence $(P<0.01)$ assuming a Poisson distribution of neuronal discharges. A: type I cell characterized by a small hump above the limit of confidence and an ABS of $<3$ spikes (e.g., cell \#S11B05nc2, firing rate $=1.9$ spikes $/ \mathrm{s}$, Fano factor $=2.0$ ). $B$ : type II cell characterized by a medium hump above the limit of confidence (e.g., cell \#A22B05nc1, firing rate $=5.3$ spikes $/ \mathrm{s}$, Fano factor $=2.4)$. $C$ : type III cell is indicated by a large hump and an average ABS of $>4$ spikes (e.g., cell \#S11B07oc1, firing rate = 3.9 spikes/s, 812 Fano factor $=5.2$ ). $D$ : type IV cell shows no hump and has an ABS of 1 (e.g., cell \#G21B12nc1, firing rate $=2.4$ spikes/s, Fano factor $=1.2$ ). Horizontal full scale bars of the raster plots correspond to $400 \mathrm{~ms}$.
A

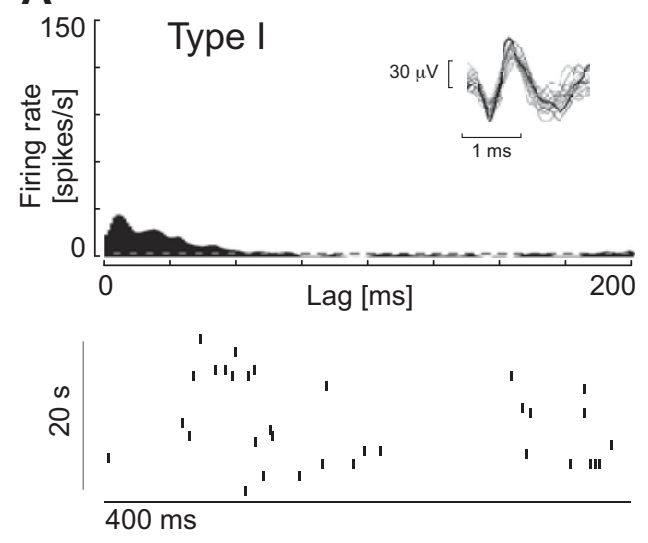

B

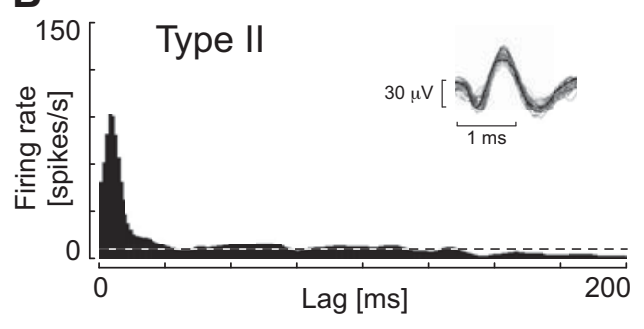

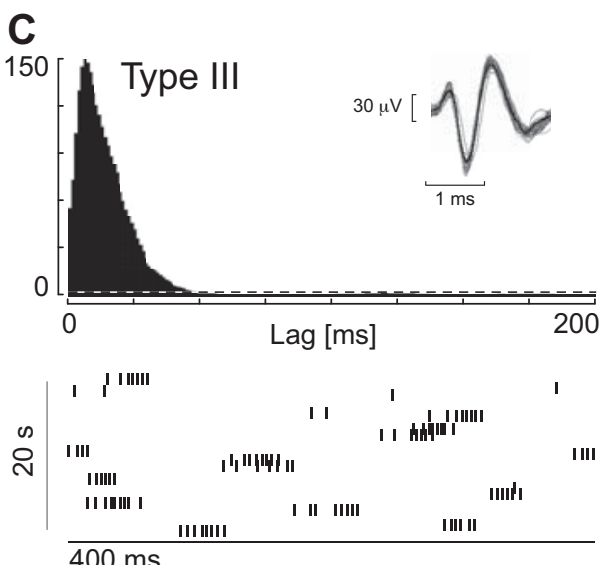

D
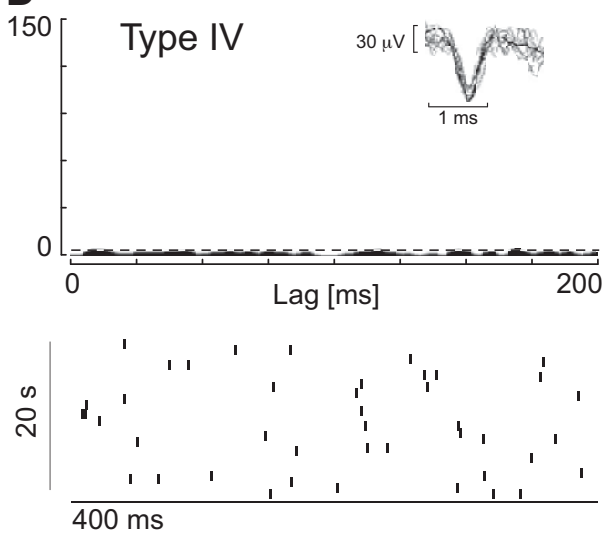
validation (Efron 1983), and the second factor (2 levels) is the genotype (i.e., WT and PVKO). The repeated measures were not significantly different $[F(1,12)=2.74, \mathrm{~ns}]$, thus suggesting that the sample from a single animal did not influence the distribution among the firing types. The interaction between the genotype and the firing types was significant $[F(3.36)=$ $56.72, P<0.001]$. In the WT group the type II cells (37\%) was the most common type, whereas type I, III and IV cells $(24,20$, and $19 \%$, respectively) were almost equally represented. In the PVKO mice type II cells $(56 \%)$ were overrepresented compared with WT, followed by type I (19\%) and type IV (15\%), whereas the least represented group was type III (10\%; Table 1). This indicates that the absence of PV leads to an increase of discharges in medium to short bursts at the expenses of longer bursts, whereas the amount of tonically firing cells tended to remain unaffected.

The increase of the selective effect on the average burst size for type II and type III cells pooled together was confirmed by analyzing the ratio of change calculated as the bin-by-bin difference between the WT and PVKO histogram of ABS, presented in Fig. 5. A negative value towards shorter bursts and a positive value of the ratio of change towards longer bursts confirm that the absence of PV leads to an increase of discharges in medium-to-short bursts at the expenses of longer bursts. Moreover, Fig. 5 shows a bimodal distribution of the rate of change, thus conforming that type II and type III correspond to two distinct firing modes that are affected in the same way by the absence of PV.

\section{$C a_{v} 3.2$ Differential Expression in PVKO and WT RTN}

We investigated the expression of the LVA $\mathrm{Ca}^{2+}$ channels $\mathrm{Ca}_{\mathrm{v}} 3.2$ (Fig. 6, $A$ and $B$ ) and $\mathrm{Ca}_{\mathrm{v}} 3.3$ (Fig. 6, $C$ and $D$ ), which are specifically expressed in the rodent RTN (Talley et al. 1999) and display different activation and inactivation kinetics (Gomora et al. 2002; Park et al. 2004) associated with the generation of the bursts of spikes. The somatic expression of

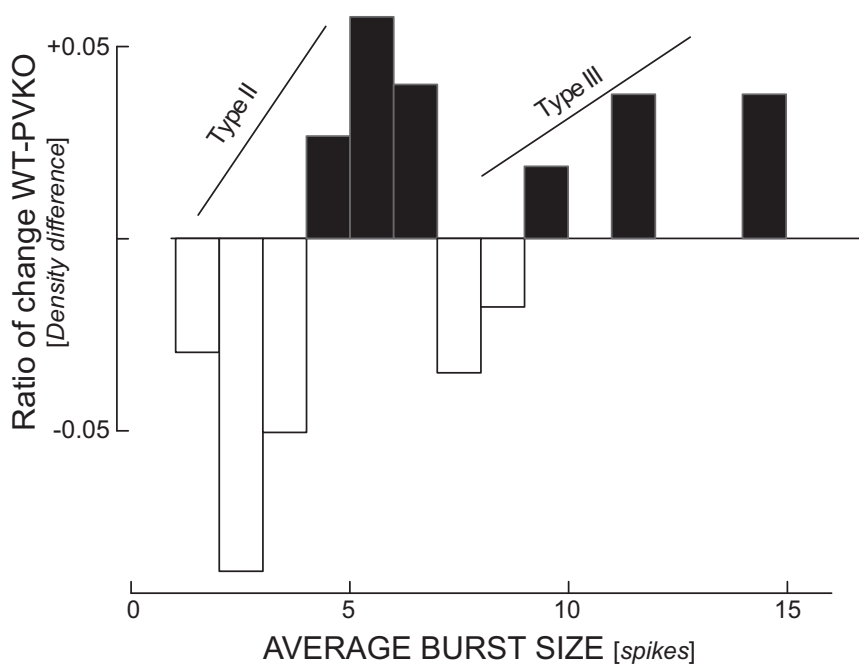

Fig. 5. Ratio of change in ABS betweenWT and PVKO. This figure represents the bin by bin difference (bin size of 1 spike) in relative frequency (density) of the histogram of the ABS of type II and type III cells pooled together. Notice that a negative value for small burst sizes means that small burst sizes were more frequently observed in PV-deficient mice. The 2 groups of negative bins, centered on 3 and 8 spikes, correspond to this effect on type II and type III, cells, respectively.
$\mathrm{Ca}_{\mathrm{v}} 3.2$ in WTs ( $n=12$ sections from 3 mice, 10 ROIs/section) and PVKOs ( $n=12$ sections from 4 mice, 10 ROIs/section) was on average equal to $67 \pm 3$ (means \pm SE) and $92 \pm 4$ pixels $/ \mu \mathrm{m}^{2}$, respectively. For the dendrites we observed an expression equal to $57 \pm 5$ and $54 \pm 3$ pixels $/ \mu \mathrm{m}^{2}$ for WT and PVKO mice, respectively. The difference in the somatic localization of $\mathrm{Ca}_{\mathrm{v}} 3.2$ (Fig. 6, $A$ and $B$ ) was statistically significant (Wilcoxon rank sum test, $\mathrm{W}=12,2 P<0.001$ ), whereas no difference was found for the dendritic localization (Wilcoxon rank sum text, $\mathrm{W}=68,2 P=0.885$ ).

To confirm that the $\mathrm{Ca}_{\mathrm{v}} 3.2$-positive puncta observed in the immunohistochemistry represent channels that are localized at active synapses, we carried out immunoelectron microscopy on RTN tissue using the $\mathrm{Ca}_{\mathrm{v}} 3.2$ antibody. We carried out a qualitative analysis and imaged a minimum of three areas for each of the three grids obtained from 2 WT and 2 PVKO RTN tissues. The 3 images are therefore representative of 18 pictures per genotype. We observed that the $\mathrm{Ca}_{\mathrm{v}} 3$.2-positive immunoprecipitate was often concentrated at asymmetric axosomatic synapses with very little cytoplasmic appearance (Fig. 7, $A$ and $B$ ), whereas symmetric synapses were devoid of any signal (Fig. 7A). The precipitate was also evident at distal axodendritic synapses, as expected (Fig. 7C).

The pattern of expression of $\mathrm{Ca}_{\mathrm{v}} 3.3$ channel appeared unaltered, and no significant difference was found between WT ( $n=12$ sections from 3 mice, 10 samples/section) and PVKO ( $n=12$ sections from 3 mice, 10 samples/section) both at somatic (70 \pm 7 and $66 \pm 8$ pixels $/ \mu \mathrm{m}^{2}$, respectively) and dendritic levels ( $68 \pm 7$ and $59 \pm 5$ pixels $/ \mu \mathrm{m}^{2}$, respectively) (Fig. 6, $C$ and $D$ ).

\section{Interaction Between Pairs of Cells}

To assess the functional network connectivity in the RTN we performed cross-correlation analysis between the spike train of pairs of cells recorded simultaneously according to the shape of the cross-renewal densities (CRD) (Abeles 1982). We discarded all cross-correlograms $(n=21$ in WTs, $n=21$ in PVKOs) computed with one or both spike trains belonging to the group of slow-firing rate, because of their insufficient spike count able to provide a meaningful statistics. Hence, the total number of cell pairs recorded at the same recording site in WT and PVKO mice was $n=70$ and $n=78$, respectively. We observed that $43(61 \%)$ and $53(68 \%)$ CRD histograms did not show any significant sign of interaction in WT and PVKO, respectively (Table 2). The independence of the firing of two units corresponded to a flat curve, and this class of histograms was termed "no interaction" (NOI). The most frequent significant type of interactions was labeled "common input" (CI), characterized by a symmetrical hump near zero lag, indicating that the simultaneously recorded cells tended to fire synchronously (Fig. 8). This interaction was observed in $31 \%(n=22)$ and $31 \%(n=24)$ of the units sampled in WT and PVKO mice (Table 2). The "other interactions" (OI) group was seldom observed ( $n=5$ and $n=1$ in WT and PVKO, respectively) and included CRD shapes characterized by very broad or unilateral sharp humps.

The interaction between the cell types defined by their background firing pattern (i.e., type I, II, III, and IV) and the group of interaction (i.e., NOI and $\mathrm{CI}$ ) was assessed when 
Cav3.2
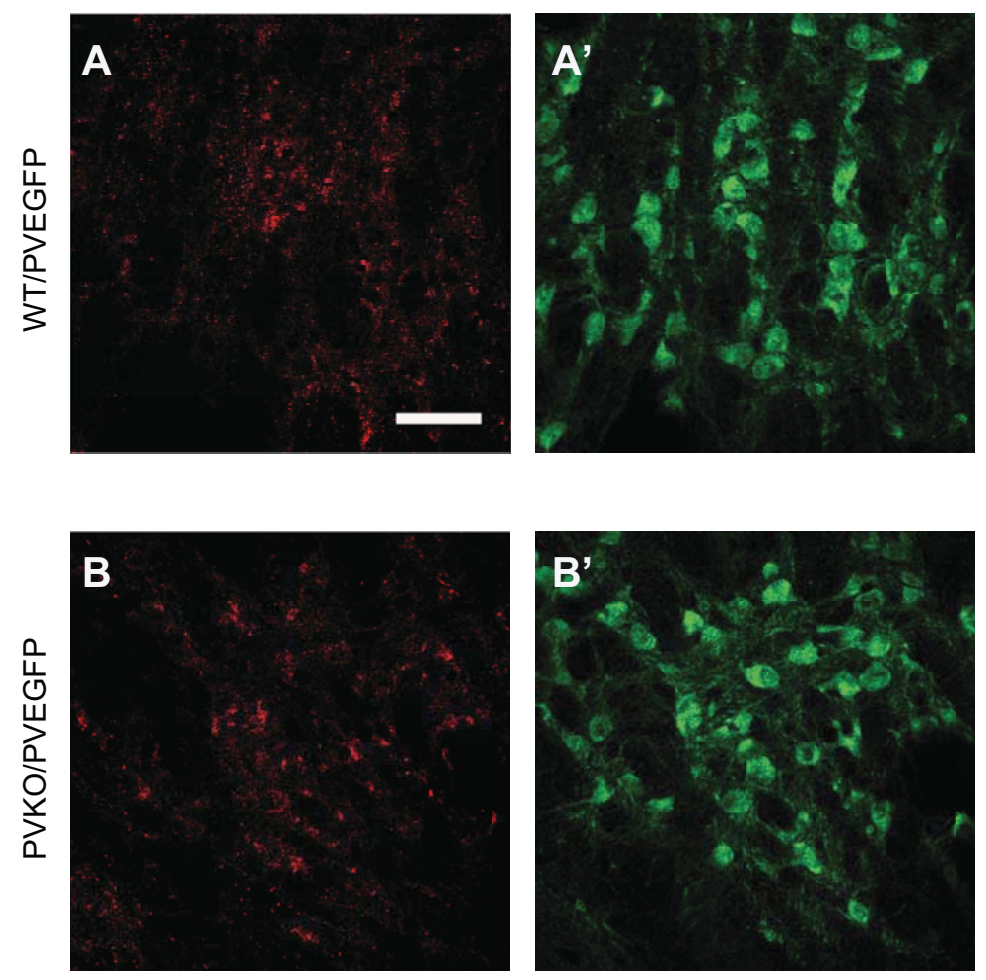

Cav3.3
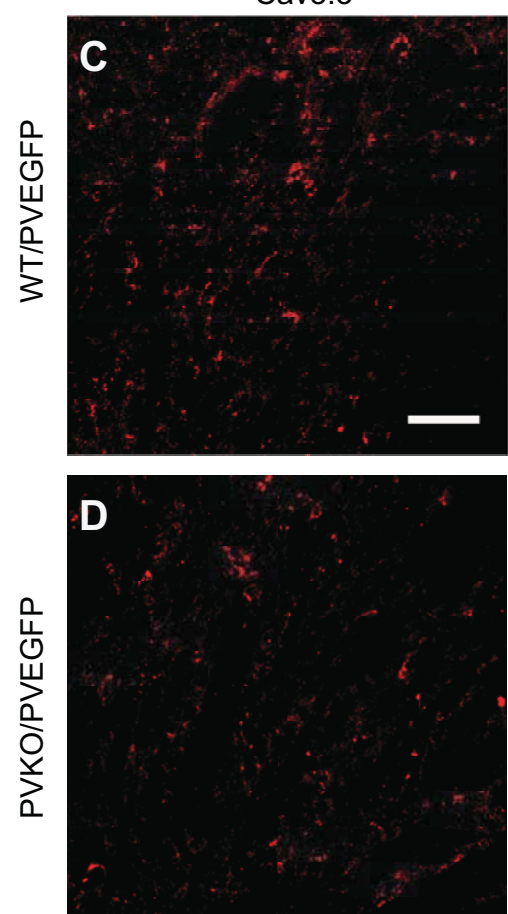

PVEGFP

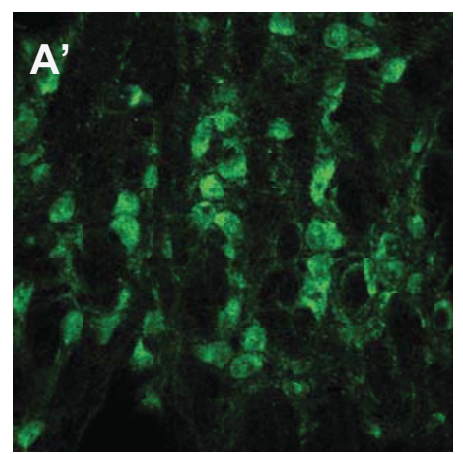

PVEGFP
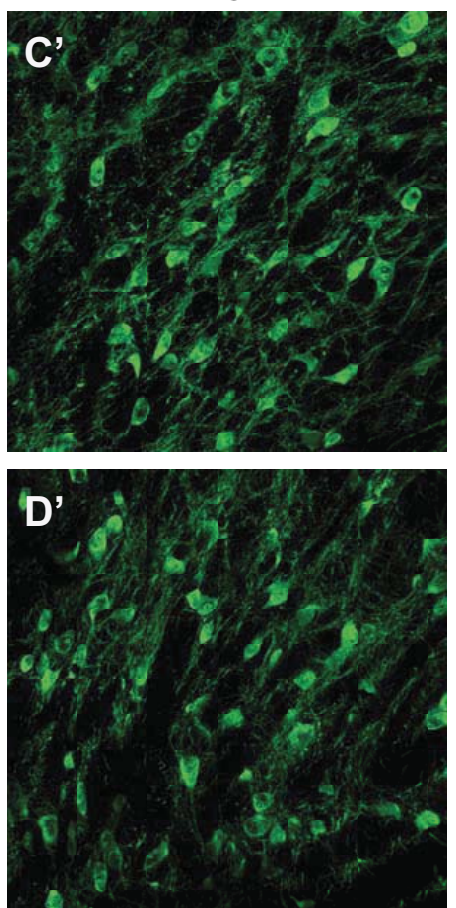
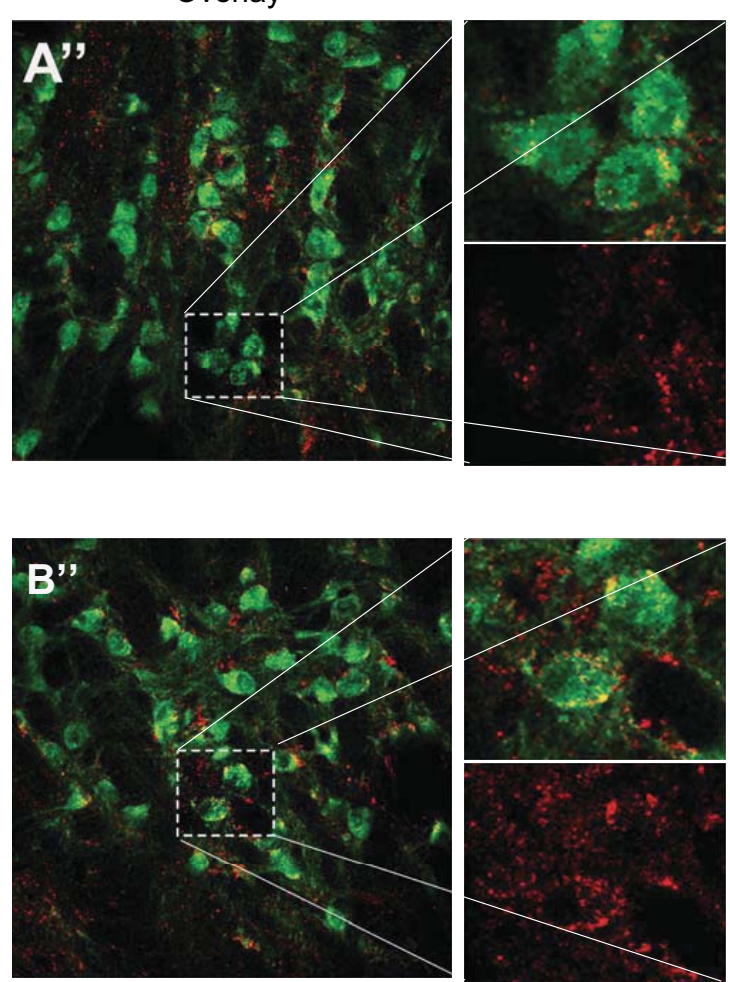

Overlay
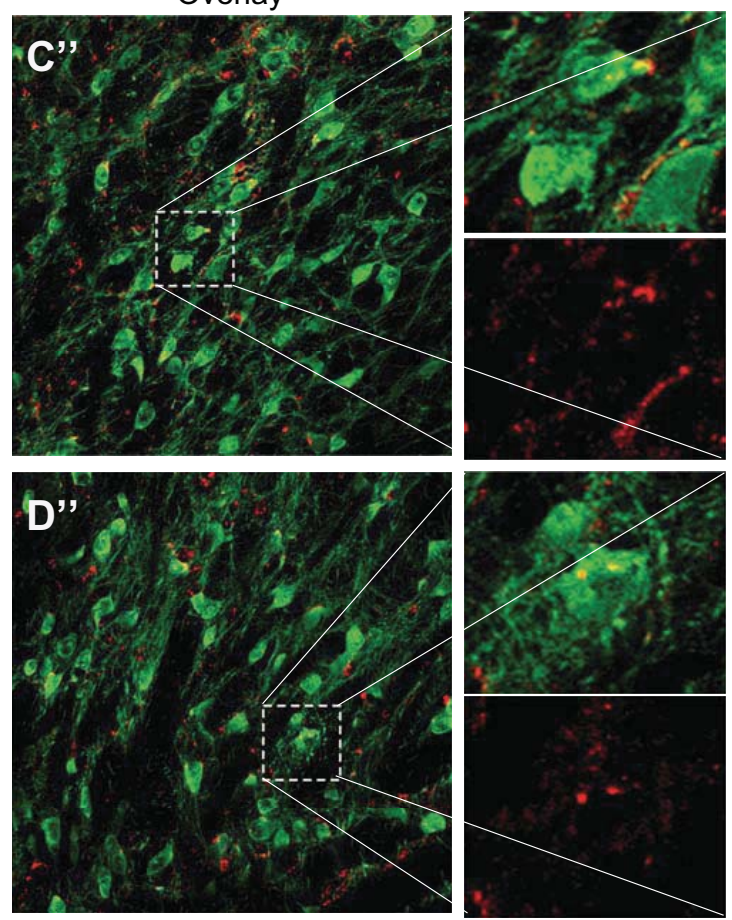

Fig. 6. Differential expression of $\mathrm{Ca}_{\mathrm{v}} 3.2$ in PVKO RTN. $A$ and $B$ : fluorescence immunohistochemistry using $\mathrm{Ca}_{\mathrm{v}} 3.2$ - and EGFP-specific antibodies shows that $\mathrm{Ca}_{\mathrm{v}} 3.2$ is enriched in the soma of PV-EGFP-positive neurons in PVKO RTN. Close-up captions highlights the somal enrichment of Ca 3.2 in PV-EGFP -positive neurons of PVKO compared with WT mice. $C$ and $D: \mathrm{Ca}_{\mathrm{v}} 3.3$ and EGFP double immunofluorescence shows that there is no detectable difference in $\mathrm{Ca}_{\mathrm{v}} 3.3$ expression between WT and PVKO. Close-up captions show a comparable $\mathrm{Ca}_{\mathrm{v}} 3.3$ distribution in PV-EGFP-positive neurons of the WT and PVKO RTN. The analysis of $\mathrm{Ca}_{\mathrm{v}} 3.2$ and $\mathrm{Ca}_{\mathrm{v}} 3.3$ was restricted to randomly selected regions of interest either on the cell soma of PV-EGFP-positive cells and PV-EGFP-positive processes of WT and PVKO specimens. Scale bar in $A$ and $C$ is $50 \mu \mathrm{m}$. 


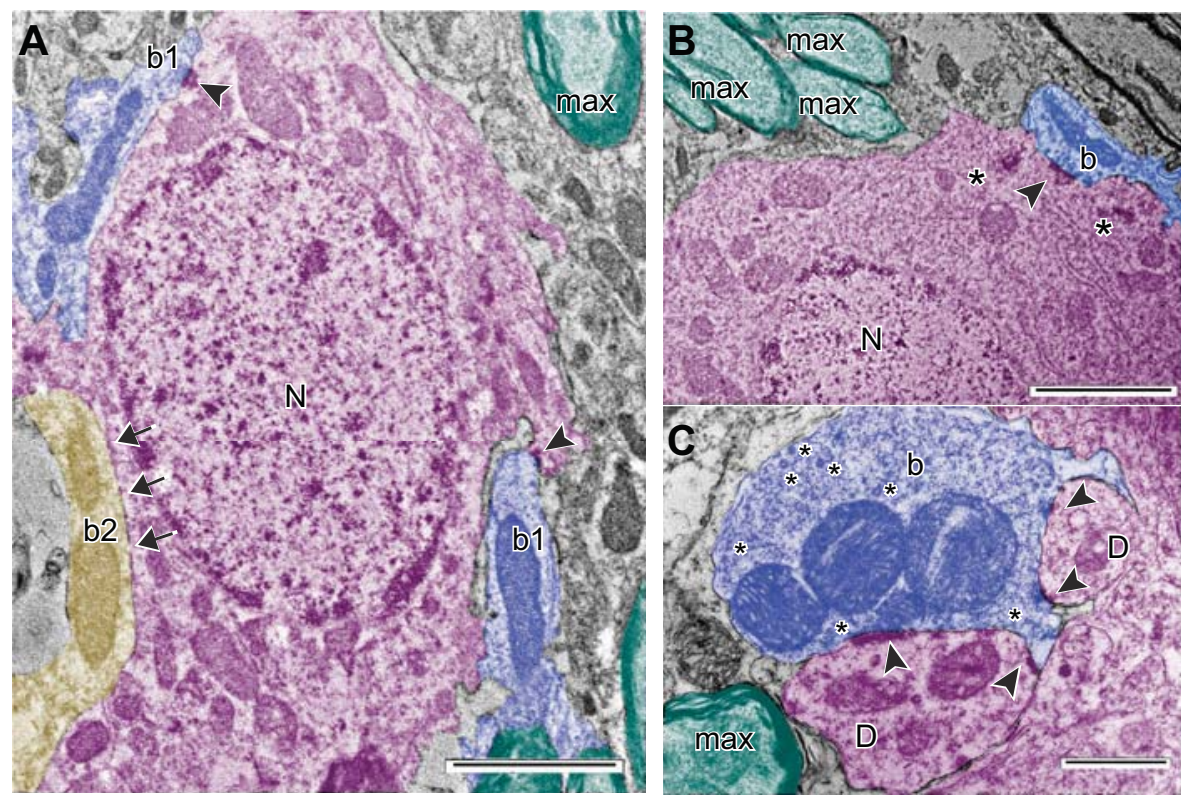

Fig. 7. Immunoelectron micrographs confirming the presence of $\mathrm{Ca}_{\mathrm{v}} 3.2$ at asymmetric axosomatic as well as axodenritic synapses in $\mathrm{RTN}$ neurons. $A$ : Ca 3.2 immunoreactive perikaryon (pink). "b2" Represents a putatively inhibitory bouton, without prominent postsynaptic densities, making symmetric contacts (arrows); "b1" appear to make asymmetric synaptic contacts (arrowheads, max): myelinated axon. Beside its diffuse nuclear ("N") and cytoplasmic distribution, the precipitate also localizes at the thick postsynaptic densities of these asymmetric contacts (arrowhead). $B$ : slightly positive neuronal cell body from a different sample flanked by a terminal axon giving rise to an en passant bouton ("b"). Note the large dense core vesicles within the presynaptic swelling and the asymmetric synaptic contact (arrowheads). Ca 3.2 immunoprecipitate (*) is located subplasmalemmally and is particularly present at the postsynaptic density. $C$ : detail of a Ca 3.2 immunoreactive dendrite ("D") contacted by a large bouton ("b") making multiple asymmetric synaptic contacts (arrowheads). Dense core vesicles within the bouton (*) and immunopositive postsynaptic densities (arrowheads) are visible. Cell body or dendrites of RTN neurons are colored in violet, asymmetric boutons in blue, the symmetric bouton in yellow, and myelinated axons in green. Scale bar in $A$ and $B=2 \mu \mathrm{m}$. Scale bar in $C=1 \mu \mathrm{m}$.

removing the effect of the genotype $\left(\chi^{2}=27.68, \mathrm{df}=6,2 P<\right.$ 0.001 ; Table 2). This means that the firing types were not equally distributed among the interaction groups. Indeed, we observed that for both genotypes, type I and type IV cells were associated with NOI, whereas type II and type III were associated with CI. This effect is due to the multiple spikes within a burst that increase the chance of a synchronous activity between two bursty cells. We observed a significant correlation (assessed by Spearman's rank correlation) between the observed and expected cell-type distributions among the interaction groups [WT mice, $\mathrm{S}=40.128, P<0.001, r_{s}(10)=0.860$; PVKO mice, $\left.\mathrm{S}=16.880, P<0: 001, r_{s}(10)=0.941\right]$. This means that given the sampled cell types and the overall interaction groups, the observed and expected distributions were similar. On the whole, the pattern of interactions between pairs of cells in the RTN of PVKO mice was not significantly different from that in WT mice indicative of unchanged functional connectivity.

\section{DISCUSSION}

The RTN is the gateway of sensory transmission in the thalamocortical and corticothalamic axes (Jones 1975, 2002). It consists of a thin sheet of cells surrounding the anterolateral part of the thalamus, which makes it a difficult target for an electrophysiological study performed in vivo with microelectrode penetrations. The present study presents in vivo recordings of RTN neurons in ketamine anesthetized mice, for the first time to our knowledge. The only other study reporting in vivo RTN extracellular single unit recording from mice was performed under pentobarbital and urethane anesthesia (Liao et al. 2011). In rats, in vivo recordings of RTN neurons were performed under pentobarbital, urethane, ketamine, or halothane anesthesia aiming primarily to study the comparative response to nociceptive stimuli in RTN and in the ventroposterior lateral nucleus of the thalamus (Yen and Shaw 2003). Other studies on mouse RTN performed in vivo have reported results on multiunit activity, local field potentials, and EEG

Table 2. Observed and theoretical distributions of the RTN cells

\begin{tabular}{|c|c|c|c|c|c|c|c|c|c|c|c|c|}
\hline \multirow[b]{2}{*}{ Genotype } & \multicolumn{3}{|c|}{ Type I } & \multicolumn{3}{|c|}{ Type II } & \multicolumn{3}{|c|}{ Type III } & \multicolumn{3}{|c|}{ Type IV } \\
\hline & NOI & $\mathrm{CI}$ & $\mathrm{OI}$ & NOI & $\mathrm{CI}$ & OI & NOI & $\mathrm{CI}$ & OI & NOI & CI & $\mathrm{OI}$ \\
\hline \multicolumn{13}{|l|}{$\mathrm{WT}(n=70)$} \\
\hline Observed & 12 & 3 & 0 & 11 & 10 & 4 & 4 & 8 & 1 & 16 & 1 & 0 \\
\hline Expected & 9 & 5 & 1 & 15 & 8 & 2 & 8 & 4 & 1 & 11 & 5 & 1 \\
\hline \multicolumn{13}{|c|}{$\operatorname{PVKO}(n=78)$} \\
\hline Observed & 13 & 1 & 0 & 30 & 16 & 1 & 3 & 6 & 0 & 7 & 1 & 0 \\
\hline Expected & 10 & 4 & 0 & 32 & 14 & 1 & 6 & 3 & 0 & 5 & 3 & 0 \\
\hline
\end{tabular}

Observed and theoretical distributions of the RTN cells into classes of interactions for normal (WT) and PVKO mice. NOI, no interaction; CI, common input; OI, other interactions. Statistics are described in the text. 
A

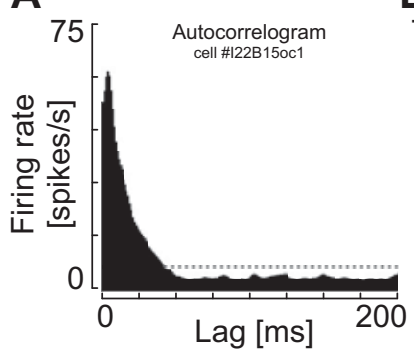

B

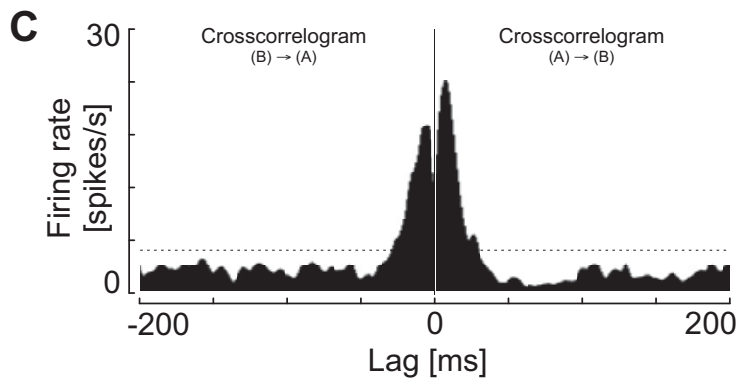

D

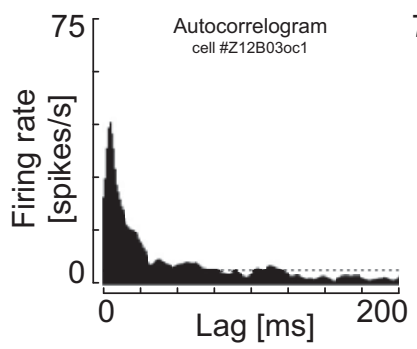

E

$\mathbf{F}$

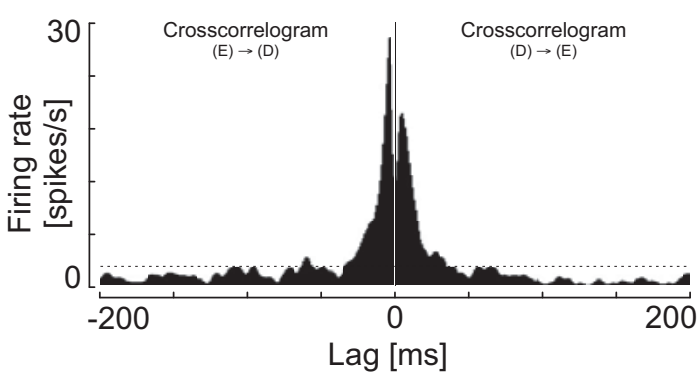

Fig. 8. Auto- and cross-renewal density histograms of a cell pair of type II units recorded in WT $(A-C)$ and a cell pair of type II units recorded in PVKO $(D-F)$ mice. Notice that both pairs $(C$ and $F)$ show a correlogram characterized by a hump centered near lag zero, typical of the common input (CI) type. Curves are smoothed by a Gaussian bin of $5 \mathrm{~ms}$. Dotted line indicates the upper limit of confidence $(P<0.01)$ assuming a Poisson distribution of neuronal discharges. A: autocorrelogram of cell \#I22B15oc1 (firing rate $=5.0$ spikes/s, Fano factor $=2.5$ ). $B$ : autocorrelogram of cell \#I22B15oc2 (firing rate $=2.1$ spikes/s, Fano factor $=2.0)$. $C$ : cross-correlogram assuming cell \#I22B15oc2 firing after cell \#I22B15oc1 for the positive scale of the lag axis and cell $\#$ I22B15oc1 firing after cell \#I22B15oc2 for the negative lag axis. D: autocorrelogram of cell \#Z12B03oc1 (firing rate $=3.0$ spikes/s, Fano factor $=$ 2.2). E: autocorrelogram of cell $\# Z 12 B 03$ oc2 (firing rate $=1.5$ spikes/s, Fano factor $=1.4)$. $C$ : cross-correlogram assuming cell \#Z12B03oc2 firing after cell \#Z12B03oc1 for the positive scale of the lag axis and cell \#Z12B03oc1 firing after cell \#Z12B03oc2 for the negative lag axis.

(Astori et al. 2011; Halassa et al. 2011). The RTN is characterized by a rather homogenous population of GABAergic neurons, expressing high levels of the "slow $\mathrm{Ca}^{2+}$ buffer" $\mathrm{PV}$ (Celio 1990; Schwaller 2009). Evidence exists (Huguenard and Prince 1992) that $I_{\mathrm{T}}$ currents mediated by the low-voltage $\mathrm{Ca}^{2+}$ channels $\mathrm{Ca}_{\mathrm{v}} 3.2$ and $\mathrm{Ca}_{\mathrm{v}} 3.3$ (Talley et al. 1999) are associated with the bursts of discharges that characterize most RTN cell activity. Based on previous observations showing that PV expression affected the firing properties in the cerebellum (Servais et al. 2005; Franconville et al. 2011), the hippocampus (Vreugdenhil et al. 2003), and the neocortex (Schwaller et al. 2004), we addressed the question, whether the absence of PV also influences the firing properties of RTN neurons.

\section{Four Firing Types Characterize the Mouse RTN}

Based on the histological reconstruction of the electrode penetrations and recording sites we could analyze overall 179 spike trains of cells whose location was attributed to RTN. Like any extracellular electrophysiological study we should consider a potential source of error in the identification of the precise coordinates of the recording site. Taking into consideration tissue retraction during the histological procedure, the cutting plane during brain sectioning, individual brain differences with respect to the reference atlas, and the transients in the electric field that can be detected from tungsten electrodes with an impedance of 1-2 $\mathrm{M} \Omega$, it appears reasonable to estimate that in our study the coordinates of a recording site can be reconstructed with an approximation in the order of $\pm 40 \mu \mathrm{m}$. RTN is a curved structure and even minor mistakes in the electrode track reconstruction may lead to a mistaken attribution of a cell location, in particular in a small brain such as the mouse brain. In the absence of any external stimulation (i.e., "spontaneous activity") we observed cells firing in short irregular discharges (24\%, type I) and in bursts (57\%, type II and type III) and tonic activity following a Poisson distribution (19\%, type IV). Because of the above-mentioned uncertainty associated to the precise reconstruction of the recording sites, we cannot discard that some of the units belonging to the RTN sample were recorded at the border of the nucleus and might belong to the neighboring areas. In spite of the fact that we discarded all cells whose location appeared ambiguous during the histological reconstruction we must assess the possibility that some of the firing types reported here might refer to cells not belonging to the RTN. Nevertheless, it is interesting to notice that the proportions of the firing types reported in this study are similar to those reported in the RTN of the anesthetized cat (Villa 1990).

The tonically firing neurons represent the smallest population in the mouse RTN as observed also in the cat and in rat (Contreras et al. 1992; Domich et al. 1986; Lee et al. 2007; Villa 1990). Interestingly, we found only four cells characterized by an oscillatory firing pattern in WT and none in PVKO mice. This observation could be explained by the use of the anesthetic drug ketamine, a noncompetitive $N$-methyl-D-aspartate (NMDA) receptor antagonist (Gunduz-Bruce 2009) that is likely to affect the specific NMDA currents in PV-positive interneurons (Korotkova et al. 2010). In contrast to the previous study of in vivo recording in the RTN by Liao et al. (2011) we observed lower firing rates (on average, 3.7 vs. 8.6 spikes/ s). In addition to the differences in the anesthetic procedures mentioned above, our studies differed in the type of electrodes that were used, in the sorting procedure of the waveforms of the electrophysiological signals, and in the sample size $(n=93$ in this study vs. $n=17$ ). 
The frequency of bursting neurons (type II and type III) was increased in PVKO mice (66 vs. 57\%) at the expense of both irregular (type I) and tonic (type IV) firing. Immunohistochemical analysis of a PV-EGFP reporter mouse line (Meyer et al. 2002) showed that in the RTN a minority $(6 \% \pm 1)$ of the neurons were PV negative (data not shown). It has been recently proposed that the tonically firing cells are characterized by a lower responsiveness to low $\mathrm{Ca}^{2+}$ currents, $I_{\mathrm{T}}$ (Lee et al. 2007), possibly due to a large difference in the distal vs. proximal distribution of the LVA channels $\mathrm{Ca}_{\mathrm{v}} 3.2$ and $\mathrm{Ca}_{\mathrm{v}} 3.3$, (Crandall et al. 2010), or due to the lack of $\mathrm{Ca}_{\mathrm{v}} 3.3$, which is essential for LTS (Astori et al. 2011). On the whole it appears that this cell population has physiological properties that are distinct from the bursting types and are independent of the presence of PV.

Despite a relatively large sample size we observed a homogenous distribution of the different cell types (defined by their discharge properties) within the mouse RTN, both along the dorsal-ventral and medial-lateral axes. It is worth mentioning that our recordings were performed in vivo in the anterior tier of the RTN (approximately corresponding to the limbic and somatosensory portion of the nucleus; Jones 1975, 1991), whereas the studies that defined a spatial organization of neurons with different firing properties within the RTN were performed in the somatosensory sector of the rat (Lee et al. 2007) and mouse slices (Lam and Sherman 2011) and in the cat dorsolateral sector (corresponding to the auditory sector, Villa 1990). Notice that the RTN is abundantly innervated by cholinergic fibers that may contribute to modulate the firing properties of its neurons in vivo (Jones 1991; Villa et al. 1996). Spatial organization of the rostral and somatotopic sector of RTN was observed on the basis of its connectivity pattern and sensory-evoked activity in several species, namely in the rat (Shosaku et al. 1984; Lozsádi 1994; Pinault et al. 1995), rabbit (Crabtree 1992), and cat (Crabtree 1996).

Our current knowledge of the RTN indicates that the connections are not the same for each sector (Guillery et al. 1998; Lam and Sherman 2011) and we do not exclude that the RTN firing types of the rostral sector of the nucleus may have a spatial organization, but a detailed and evenly distributed sample of recording sites should be collected to answer this question. Our study suggests that different firing types are present in the RTN; it remains to be understood whether these are biologically patterned or whether the same cellular type could fire in different modes according to different arousal or attentive states.

\section{Medium Bursting RTN Neurons Are Prevalent in the Absence of $P V$}

The proportion of neurons characterized by a particular firing type was significantly different in WT and PVKO mice. The medium-bursting type (type II) was observed more often (56\%) in PVKO than in WT (37\%) mice, and correspondingly type III was less numerous in PVKO (10 vs. 20\%). Hence, in PVKO mice we observed a prevalence of medium size bursts ( $\approx 3$ spikes) compared with longer bursts ( $\approx 6$ spikes). The intraburst frequency was lower in PVKO than in WT for both bursting type of neurons (type II and type III), because for each type the average burst duration was longer in the PVKO cells, with a similar number of spikes per burst in WT and PVKO.
This indicates that the lack of PV mostly affects the firing properties of neurons with characteristic burst discharges. As reported elsewhere, the number of spikes in a burst is correlated with the magnitude of $I_{\mathrm{T}}$ currents, while the spike interval is set by the time to reach the maximal $\mathrm{Ca}^{2+}$ amplitude in a burst (Perez-Reyes 2003).

In RTN neurons the bursting activity is associated with the hyperpolarization-activated LVA channels. Indeed in RTN neurons from $\mathrm{Ca}_{\mathrm{v}} 3.3 \mathrm{KO}$ mice (Astori et al. 2011), $I_{\mathrm{T}}$ currents are reduced by $\sim 80 \%$, and the bursting properties are almost completely abolished. Moreover, apamin-sensitive currents mediated by SK2 were dramatically reduced in $\mathrm{Ca}_{\mathrm{v}} 3.3 \mathrm{KO}$ mice, indicating that $\mathrm{Ca}_{\mathrm{v}} 3.3$ channels, characterized by slower activation and inactivation kinetics compared with $\mathrm{Ca}_{\mathrm{v}} 3.2$, are required for the coupling between T and SK2 channels in RTN neurons. Both, fast and slow $\mathrm{Ca}^{2+}$ buffers (BAPTA and EGTA, respectively) block the apamin-sensitive SK currents in RTN neurons without affecting $I_{\mathrm{T}}$ currents (Cueni et al. 2008). In a model of striatal fast spiking interneurons (Bischop et al. 2012), a reduction in $\mathrm{Ca}^{2+}$ buffering by PV leads to an increased firing rate associated with altered activation of SK channels, thus suggesting that a similar phenomenon may take place in the PVKO mice. Hence, we expect that PV has a comparable impact on RTN neurons' SK currents.

Our in vivo recordings showed that in PVKO mice a higher proportion of RTN neurons was characterized by a firing mode with medium (type II) rather than long (type III) bursts. This might be caused either by the absence of PV or by the homeostatic compensation mechanisms underlying the altered cellular distribution of $\mathrm{Ca}_{\mathrm{v}} 3.2$. Interestingly, the firing phenotype of PVKO RTN neurons showed large similarities to the one seen in $\mathrm{Ca}_{\mathrm{v}} 3.2 \mathrm{KO}$ neurons (Liao et al. 2011): the burst duration was increased, caused by a larger interval between spikes, without affecting the spike number within a burst. Ablation of the $\mathrm{Ca}_{\mathrm{v}} 3.2$ channel, a LVA channel type characterized by fast activation and inactivation kinetics (Kozlov et al. 1999), provokes $I_{\mathrm{T}}$ to be mediated by the "slower" variant, $\mathrm{Ca}_{\mathrm{v}} 3.3$, hence leading to the observed phenotype. The increase in burst duration for type II and III neurons from 45-50 to 70-75 ms observed in PVKO could be due an increase in time necessary to reach maximal $\left[\mathrm{Ca}^{2+}\right]_{\mathrm{i}}$. It has been shown that in $\mathrm{Ca}_{\mathrm{v}} 3.3 \mathrm{KO}$ mice a reduction in $I_{\mathrm{T}}$ currents provokes a reduction in the number of spikes per burst (PerezReyes 2003), which would correspond to a switch from type III to type II (as observed in PVKO mice). It appears, however, unlikely that this effect results from the absence of $\mathrm{PV} \mathrm{Ca}^{2+}$ buffering, because $I_{\mathrm{T}}$ currents were unaffected in RTN neurons even with a blockade of SK currents by high BAPTA concentration ( $5 \mathrm{mM}$ ) (Cueni et al. 2008). Hence, the reduction in the number of spikes per burst in PVKO neurons could be due to a decreased $I_{\mathrm{T}}$ associated with PV-induced remodeling rather than a direct effect of the absence of PV.

\section{Ca 3.2 Are Enriched in the Somatic Region of PVKO RTN Neurons}

Based on the commonalities of the PVKO and $\mathrm{Ca}_{\mathrm{v}} 3.2 \mathrm{KO}$ phenotype (Liao et al. 2011) with respect to RTN bursting firing properties we investigated the possibility that in the absence of PV alteration in $\mathrm{Ca}_{\mathrm{v}} 3.2$ and $\mathrm{Ca}_{\mathrm{v}} 3.3$ channel distribution and/or expression may occur in RTN neurons. To 
restrict our analysis to "PV-ir" RTN neurons also in the absence of PV, we took advantage of a transgenic mouse line that expresses EGFP under the control of the PV promoter (gene symbol: Pvalb) (Meyer et al. 2002). In PVKO mice, $\mathrm{Ca}_{\mathrm{v}} 3.2$ but not $\mathrm{Ca}_{\mathrm{v}} 3.3$ was enriched in somatic regions, whereas the dendritic distribution of both channel types appeared unchanged in PVKO mice.

Immunoelectron microscopy on RTN sections revealed that the somatic puncta, observed by confocal microscopy, are likely to represent active channels located at synapses and not proteins trafficked in recycling endosomes or de novo synthesized/modified at the endoplasmic reticulum/Golgi compartments. The $\mathrm{Ca}_{\mathrm{v}}$ 3.2-positive immunoprecipitate was concentrated at axosomatic and axodendritic synapses with very little cytosolic localization. Thus a higher density of somatic Cav3.2 channels is expected to modify the spatiotemporal aspects of somatic and possibly dendritic $\mathrm{Ca}^{2+}$ signals of PVKO RTN neurons. This, in turn, may affect the kinetics of activation of SK channels as well as $\mathrm{Ca}^{2+}$ uptake and extrusion systems.

Another possibility is that a putative reduction in dendritic vs. somatic expression of $\mathrm{Ca}_{\mathrm{v}} 3.2$ favors the activation of the slower Cav3.3 channels in dendrites leading to a situation resembling the one reported in the $\mathrm{Ca}_{\mathrm{v}} 3.2 \mathrm{KO}$ mice (Liao et al. 2011). Altogether in $\mathrm{KO}$ mice for the various $\mathrm{Ca}^{2+}$ signaling components, $\mathrm{Ca}_{\mathrm{v}} 3.2, \mathrm{Ca}_{\mathrm{v}} 3.3, \mathrm{SK} 2$, and $\mathrm{PV}$, the firing properties of those neurons are profoundly affected. It remains to be clarified whether the effect on the distribution of the $\mathrm{Ca}_{\mathrm{v}} 3.2$ channels is a direct consequence of PV loss or an indirect effect as a result of the altered $\left[\mathrm{Ca}^{2+}\right]_{i}$ dynamics in the absence of PV.

\section{Effect of the Preparation on Firing Synchronicity}

Simultaneous activity of neighboring pairs of neurons can be recorded by the same microelectrode by means of spike sorting (Lewicki 1998). We observed that about two-thirds of the neuronal pairs, in both WT and PVKO mice, showed no sign of interaction in the cross-correlograms. The remaining third of interactions showed signs of synchronous firing, characterized by a curve with a symmetrical hump near lag zero, a proportion similar to the one previously reported in the RTN of the cat (Villa 1990). Of note the cell types involved in the synchronized correlograms tended to belong to the bursting cells (type II and type III) more often than expected on the basis of an independent sampling. The shape of the autocorrelograms of the cells making up the pair may affect the shape of their cross-correlogram (Knox and Poppele 1977; Eggermont 1990). The firing rate of the recorded neurons (3-4 spikes/s) decreases the chances of an artefact due to a misidentification of the overlapped spikes associated to the spike sorting procedure (Bar-Gad et al. 2001) and increases the likelihood that the firing synchronicity reveals a functional connection associated to a common input projecting to the neurons making up the pair (Aertsen and Gerstein 1985).

In WT mice anesthetized with ketamine, it was reported that synchronicity was decreased in the cerebellum, whereas in mice lacking other $\mathrm{Ca}^{2+}$-binding proteins (i.e., calretinin and calbindin D-28k) an increase in simple-spike rate of Purkinje cells with respect to WT was observed, accompanied by faster and amplified rhythmicity (Cheron et al. 2004; Servais and Cheron 2005). It is important to discuss whether the absence of modification in the firing synchronicity that we observed between pairs of RTN cells in PVKO with respect to WT is due to the anesthetized preparation. In a comparative study of the effects of various general anesthetics in mice, it was indicated that the combination of ketamine and xylazine is considered the most reliable for anesthesia of mice, despite that respiration was moderately decreased and the cardiovascular system was strongly depressed (Erhardt et al. 1984). With the use of combined simultaneous in vivo intracellular and extracellular recording techniques, it was observed that ketamine/xylazine anesthesia induced slow oscillations (in local field potentials in the olfactory bulb and piriform cortex as well as in pyramidal cell membrane potentials in the piriform cortex) that are correlated with the natural breathing cycle of the rat and therefore appear to be directly related to ongoing periodic patterns of afferent input linked to respiration (Fontanini et al. 2003). There is evidence that ketamine at doses comparable to ours (ketamine; $50 \mathrm{mg} / \mathrm{kg}$ ) increases hippocampal activity in rat CA1 and delta oscillations as a result of input from the thalamus (Zhang et al. 2012). Anesthesia induced by ketamine/ xylazine in mice showed different regional effects in the thalamus (Kim et al. 2012), i.e., that the ventral lateral thalamus Granger-caused the primary motor cortex and the primary somatosensory cortex, whereas the primary somatosensory cortex consistently Granger-caused the ventrobasal thalamus, regardless of the loss of consciousness.

The absence of increased synchronicity in RTN of PVKO compared with WT that is reported in the current study is also in agreement with the fact that PVKO mice do not present spontaneous epileptic seizures but an increased susceptibility to epileptic seizures (Schwaller et al. 2004). A series of classical studies on the cat's spindling activity RTN cells were recorded under ketamine/xylazine anesthesia (Contreras and Steriade 1995, 1996) and showed spontaneous burst firing with rather weak synchrony within the frequency range of spindles. In those studies the stimulation of the motor cortex induced stronger spindling oscillation that was synchronous among the pair of RTN cells recorded simultaneously. The prolonged hyperpolarizations, either spontaneous or stimulus elicited, are effective in setting the scene for widespread synchronization in thalamocortical networks. In PVKO we observed indeed an increase in average burst duration of RTN neurons setting the condition for an increased susceptibility to spindling oscillations without the need of an increase in spontaneous synchronicity. Despite the limitation of a study with an anesthetic model like ours, we suggest that our ketamine/xylazine anesthetized preparation did not alter the significance of the comparison of RTN synchronicity between PVKO and WT mice.

\section{Functional Connectivity of RTN Neurons Is Unchanged in PVKO Mice}

Our results show that functional connectivity appears to be unaffected by PV ablation, and the question arises whether the common source of input to firing synchronicity, whenever observed, lies within RTN or comes from an external input. It is known that RTN is characterized by a pattern of collaterals establishing axodendritic, somatodendritic, and dendrodendritic synapses within the RTN (Csillik et al. 2005; Spreafico et al. 1991; Steriade et al. 1984; Yingling and Skinner 1976). These collaterals are $\mathrm{GABAergic}$, expressing $\operatorname{GABA}(\beta 3)$ as 
opposed to the RTN projections onto the thalamocortical (TC) cells that express $\operatorname{GABA}(\beta 3)$ (Liu et al. 2007; Sohal and Huguenard 2003). Recent findings have shown that these collateral synapses within RTN are likely to be much weaker than the RTN-TC synapses (Lam et al. 2006). Despite the observation of gap junctions between RTN neurons (Landisman et al. 2002), their ability to propagate the activity over the nucleus is likely to be less important than the dominant form of reticulo-reticular connectivity driven by axodendritic synapses (Lam et al. 2006). Therefore, the intra-RTN connections are likely to contribute marginally to synchronization of cell pairs during spontaneous activity.

The main sources of common inputs to RTN cell pairs are the collaterals from the thalamic relay cells and the collaterals of the corticothalamic fibers. It is possible that pyramidal cell activity is somehow modified in the PVKO mice because of the major role played by PV-expressing cortical interneurons on the shaping of the pyramidal cell output in WT animal (Runyan et al. 2010; Atallah et al. 2012). However, only a stimulation paradigm associated to simultaneous recordings in the cortex and in RTN could provide some answers to that question. Moreover, the synaptic strength of the corticothalamic collaterals is much weaker than the synaptic strength of the thalamocortical collaterals (Liu et al. 2001). In light of our results we suggest that the positive cross-correlograms showing synchronized activity are the result of the thalamocortical collaterals to the RTN (Villa et al. 1999; Lam and Sherman 2011). Thus, in the absence of PV, the functional connectivity of RTN during spontaneous activity would remain unaffected. This result is in line with the observation that PVKO mice do not show spontaneous seizures (Schwaller et al. 2004), despite the fact that the thalamus is key in controlling cortical states (Poulet et al. 2012).

Our study suggests that the lack of PV affects the firing properties and burst discharge dynamics of the main population of RTN neurons. In addition we observe that PV ablation affects the somatic vs. dendritic distribution of the $\mathrm{Ca}_{\mathrm{v}} 3.2$ channels, which may contribute to the observed phenotype. Changes in burst structure are likely to affect the information transfer gated by the inhibitory feedback projections exerted by RTN neurons on the thalamic relay cells. The outcome of this alteration could affect the transthalamic corticortical connectivity (Gollo et al. 2010; Paz et al. 2011; Sherman and Guillery 2011; Theyel et al. 2010; Villa et al. 1999) such to generate an impaired processing of the information associated to psychiatric disorders (Ferrarelli et al. 2010; Gogolla et al. 2009; Lawrence et al. 2010; Pinault 2011; Reynolds et al. 2001; Wills et al. 2011).

\section{ACKNOWLEDGMENTS}

We thank Dr. Hannah Monyer, Department of Clinical Neurobiology, University of Heidelberg for providing PV-EGFP mice. We also thank Marguerite Kaczorowski for technical assistance throughout the histological procedures, Alessandra Scotti for help in interpreting the immunoelectron microscopy pictures, and Sylvie Ducreux for comments and preliminary studies.

\section{GRANTS}

We acknowledge the support received by the Swiss National Science Foundation SNSF Grant No. 130680 (to B. Schwaller).

\section{DISCLOSURES}

No conflicts of interest, financial or otherwise, are declared by the author(s).

\section{AUTHOR CONTRIBUTIONS}

Author contributions: L.A., A.L., R.K., B.S., and A.E.V. conception and design of research; L.A. and A.L. performed experiments; L.A. and A.L. analyzed data; L.A., A.L., R.K., B.S., and A.E.V. interpreted results of experiments; L.A. and A.L. prepared figures; L.A., A.L., B.S., and A.E.V. drafted manuscript; L.A., A.L., R.K., B.S., and A.E.V. edited and revised manuscript; L.A., A.L., R.K., B.S., and A.E.V. approved final version of manuscript.

\section{REFERENCES}

Abeles M. Quantification, smoothing, and confidence limits for single-units' histograms. J Neurosci Methods 5: 317-325, 1982.

Aertsen AM, Gerstein GL. Evaluation of neuronal connectivity: sensitivity of cross-correlation. Brain Res 340: 341-354, 1985.

Aksenova TI, Chibirova OK, Dryga OA, Tetko IV, Benabid AL, Villa AE. An unsupervised automatic method for sorting neuronal spike waveforms in awake and freely moving animals. Methods 30: 178-187, 2003.

Asai Y, Aksenova TI, Villa AE. Unsupervised recognition of neuronal discharge waveforms for on-line real-time operation. Lecture Notes Comp Sci 3704: 29-38, 2005.

Astori S, Wimmer RD, Prosser HM, Corti C, Corsi M, Liaudet N, Volterra A, Franken P, Adelman JP, Lüthi A. The $\mathrm{Ca}(\mathrm{V}) 3.3$ calcium channel is the major sleep spindle pacemaker in thalamus. Proc Natl Acad Sci USA 108: 13823-13828, 2011.

Atallah BV, Bruns W, Carandini M, Scanziani M. Parvalbumin-expressing interneurons linearly transform cortical responses to visual stimuli. Neuron 73: 159-170, 2012.

Bar-Gad I, Ritov Y, Vaadia E, Bergman H. Failure in identification of overlapping spikes from multiple neuron activity causes artificial correlations. J Neurosci Methods 107: 1-13, 2001.

Behrendt RP. Dysregulation of thalamic sensory "transmission" in schizophrenia: neurochemical vulnerability to hallucinations. J Psychopharmacol 20: 356-372, 2006.

Bischop DP, Orduz D, Lambot L, Schiffmann SN, Gall D. Control of neuronal excitability by calcium binding proteins: a new mathematical model for striatal fast-spiking interneurons. Front Mol Neurosci 5: 78, 2012.

Caillard O, Moreno H, Schwaller B, Llano I, Celio MR, Marty A. Role of the calcium-binding protein parvalbumin in short-term synaptic plasticity. Proc Natl Acad Sci USA 97: 13372-13377, 2000.

Celio MR. Calbindin D-28k and parvalbumin in the rat nervous system. Neuroscience 35: 375-475, 1990.

Celio MR, Spreafico R, De Biasi S, Vitellaro-Zuccarello L. Perineuronal nets: past and present. Trends Neurosci 21: 510-515, 1998.

Cheron G, Gall D, Servais L, Dan B, Maex R, Schiffmann SN. Inactivation of calcium-binding protein genes induces $160 \mathrm{hz}$ oscillations in the cerebellar cortex of alert mice. J Neurosci 24: 434-441, 2004.

Clemence AE, Mitrofanis J. Cytoarchitectonic heterogeneities in the thalamic reticular nucleus of cats and ferrets. J Comp Neurol 322: 167-180, 1992.

Collin T, Chat M, Lucas MG, Moreno H, Racay P, Schwaller B, Marty A, Llano I. Developmental changes in parvalbumin regulate presynaptic $\mathrm{Ca}^{2+}$ signaling. J Neurosci 25: 96-107, 2005.

Contreras D, Curro Dossi R, Steriade M. Bursting and tonic discharges in two classes of reticular thalamic neurons. J Neurophysiol 68: 973-977, 1992.

Contreras D, Steriade M. Cellular basis of EEG slow rhythms: a study of dynamic corticothalamic relationships. J Neurosci 15: 604-622, 1995.

Contreras D, Steriade M. Spindle oscillation in cats: the role of corticothalamic feedback in a thalamically generated rhythm. J Physiol 490: 159-179, 1996.

Coulon P, Herr D, Kanyshkova T, Meuth P, Budde T, Pape HC. Burst discharges in neurons of the thalamic reticular nucleus are shaped by calcium-induced calcium release. Cell Calcium 46: 333-346, 2009.

Crabtree JW. The somatotopic organization within the rabbit's thalamic reticular nucleus. Eur J Neurosci 4: 1343-1351, 1992.

Crabtree JW. Organization in the somatosensory sector of the cat's thalamic reticular nucleus. J Comp Neurol 366: 207-222, 1996.

Crandall SR, Govindaiah G, Cox CL. Low-threshold $\mathrm{Ca}^{2+}$ current amplifies distal dendritic signaling in thalamic reticular neurons. J Neurosci 30: 15419-15429, 2010. 
Crick F. Function of the thalamic reticular complex: the searchlight hypothesis. Proc Natl Acad Sci USA 81: 4586-4590, 1984.

Csillik B, Mihály A, Krisztin-Péva B, Chadaide Z, Samsam M, KnyiháarCsillik E, Fenyo R. GABAergic parvalbumin-immunoreactive large calyciform presynaptic complexes in the reticular nucleus of the rat thalamus. $J$ Chem Neuroanat 30: 17-26, 2005.

Cueni L, Canepari M, Lujan R, Emmenegger Y, Watanabe M, Bond CT, Franken P, Adelman JP, Luthi A. T-type $\mathrm{Ca}^{2+}$ channels, SK2 channels and SERCAs gate sleep-related oscillations in thalamic dendrites. Nat Neurosci 11: 683-692, 2008.

DeLorey TM, Sahbaie P, Hashemi E, Li WW, Salehi A, Clark DJ. Somatosensory and sensorimotor consequences associated with the heterozygous disruption of the autism candidate gene, gabrb3. Behav Brain Res 216: 36-45, 2011.

Destexhe A, McCormick DA, Sejnowski TJ. A model for 8-10 Hz spindling in interconnected thalamic relay and reticularis neurons. Biophys $J 65$ : 2473-2477, 1993.

Domich L, Oakson G, Steriade M. Thalamic burst patterns in the naturally sleeping cat: a comparison between cortically projecting and reticularis neurones. J Physiol 379: 429-449, 1986.

Efron B. Estimating the error rate of a prediction rule: improvement on cross-validation. J Am Stat Assoc 78: 316-331, 1983.

Eggermont JJ. The Correlative Brain: Theory and Experiment in Neuronal Interaction. Berlin, Germany: Springer Verlag, 1990.

Erhardt W, Hebestedt A, Aschenbrenner G, Pichotka B, Blümel G. A comparative study with various anesthetics in mice (pentobarbitone, ketamine-xylazine, carfentanyl-etomidate). Res Exp Med (Berl) 184: 159-169, 1984.

Ferrarelli F, Peterson MJ, Sarasso S, Riedner BA, Murphy MJ, Benca RM, Bria P, Kalin NH, Tononi G. Thalamic dysfunction in schizophrenia suggested by whole-night deficits in slow and fast spindles. Am J Psychiatry 167: 1339-1348, 2010.

Fontanini A, Spano P, Bower JM. Ketamine-xylazine-induced slow $(<1.5$ hz) oscillations in the rat piriform (olfactory) cortex are functionally correlated with respiration. J Neurosci 23: 7993-8001, 2003.

Franconville R, Revet G, Astorga G, Schwaller B, Llano I. Somatic calcium level reports integrated spiking activity of cerebellar interneurons in vitro and in vivo. J Neurophysiol 106: 1793-1805, 2011.

Galarreta M, Hestrin S. Electrical and chemical synapses among parvalbumin fast-spiking gabaergic interneurons in adult mouse neocortex. Proc Natl Acad Sci USA 99: 12438-12443, 2002.

Gogolla N, Leblanc JJ, Quast KB, Sudhof T, Fagiolini M, Hensch TK. Common circuit defect of excitatory-inhibitory balance in mouse models of autism. J Neurodev Disord 1: 172-181, 2009.

Gollo LL, Mirasso C, Villa AE. Dynamic control for synchronization of separated cortical areas through thalamic relay. Neuroimage 52: 947-955, 2010.

Gomora JC, Murbartian J, Arias JM, Lee JH, Perez-Reyes E. Cloning and expression of the human T-type channel $\mathrm{Ca}(\mathrm{v}) 3.3$ : insights into prepulse facilitation. Biophys $J$ 83: 229-241, 2002.

Guillery RW, Feig SL, Lozsadi DA. Paying attention to the thalamic reticular nucleus. Trends Neurosci 21: 28-32, 1998.

Gunduz-Bruce $\mathbf{H}$. The acute effects of nmda antagonism: from the rodent to the human brain. Brain Res Rev 60: 279-286, 2009.

Halassa MM, Siegle JH, Ritt JT, Ting JT, Feng G, Moore CI. Selective optical drive of thalamic reticular nucleus generates thalamic bursts and cortical spindles. Nat Neurosci 14: 1118-1120, 2011.

Houser CR, Vaughn JE, Barber RP, Roberts E. Gaba neurons are the major cell type of the nucleus reticularis thalami. Brain Res 200: 341-354, 1980.

Huguenard JR, Prince DA. A novel T-type current underlies prolonged $\mathrm{Ca}^{2+}$-dependent burst firing in GABAergic neurons of rat thalamic reticular nucleus. J Neurosci 12: 3804-3817, 1992.

Jones EG. Some aspects of the organization of the thalamic reticular complex. J Comp Neurol 162: 285-308, 1975.

Jones EG. The anatomy of sensory relay functions in the thalamus. Prog Brain Res 87: 29-52, 1991.

Jones EG. Thalamic circuitry and thalamocortical synchrony. Philos Trans $R$ Soc Lond B Biol Sci 357: 1659-1673, 2002.

Jones EG. Synchrony in the interconnected circuitry of the thalamus and cerebral cortex. Ann NY Acad Sci 1157: 10-23, 2009.

Jones EG, Hendry SH. Differential calcium binding protein immunoreactivity distinguishes classes of relay neurons in monkey thalamic nuclei. Eur $J$ Neurosci 1: 222-246, 1989.
Kim SP, Hwang E, Kang JH, Kim S, Choi JH. Changes in the thalamocortical connectivity during anesthesia-induced transitions in consciousness. Neuroreport 23: 294-298, 2012.

Knox CK, Poppele RE. Correlation analysis of stimulus-evoked changes in excitability of spontaneously firing neurons. $J$ Neurophysiol 40: 616-625, 1977.

Korotkova T, Fuchs EC, Ponomarenko A, von Engelhardt J, Monyer H. NMDA receptor ablation on parvalbumin-positive interneurons impairs hippocampal synchrony, spatial representations, and working memory. Neuron 68: 557-569, 2010.

Kozlov AS, McKenna F, Lee JH, Cribbs LL, Perez-Reyes E, Feltz A, Lambert RC. Distinct kinetics of cloned t-type $\mathrm{Ca}^{2+}$ channels lead to differential $\mathrm{Ca}^{2+}$ entry and frequency-dependence during mock action potentials. Eur J Neurosci 11: 4149-4158, 1999.

Lam YW, Nelson CS, Sherman SM. Mapping of the functional interconnections between thalamic reticular neurons using photostimulation. $J$ Neurophysiol 96: 2593-2600, 2006.

Lam YW, Sherman SM. Functional organization of the thalamic input to the thalamic reticular nucleus. J Neurosci 31: 6791-6799, 2011.

Landisman CE, Long MA, Beierlein M, Deans MR, Paul DL, Connors BW. Electrical synapses in the thalamic reticular nucleus. $J$ Neurosci 22: 1002-1009, 2002

Lawrence YA, Kemper TL, Bauman ML, Blatt GJ. Parvalbumin-, calbindin-, and calretinin-immunoreactive hippocampal interneuron density in autism. Acta Neurol Scand 121: 99-108, 2010.

Lee SH, Govindaiah G, Cox CL. Heterogeneity of firing properties among rat thalamic reticular nucleus neurons. J Physiol 582: 195-208, 2007.

Lee SH, Schwaller B, Neher E. Kinetics of $\mathrm{Ca}^{2+}$ binding to parvalbumin in bovine chromaffin cells: implications for $\left[\mathrm{Ca}^{2+}\right]$ transients of neuronal dendrites. $J$ Physiol 525: 419-432, 2000.

Lewicki MS. A review of methods for spike sorting: the detection and classification of neural action potentials. Network 9: 53-78, 1998.

Liao YF, Tsai ML, Chen CC, Yen CT. Involvement of the Cav3.2 t-type calcium channel in thalamic neuron discharge patterns. Mol Pain 7: 43, 2011.

Liu XB, Coble J, van Luijtelaar G, Jones EG. Reticular nucleus-specific changes in alpha3 subunit protein at GABA synapses in genetically epilepsy-prone rats. Proc Natl Acad Sci USA 104: 12512-12517, 2007.

Liu XB, Murray KD, Jones EG. Low-threshold calcium channel subunit $\mathrm{Ca}(\mathrm{v}) 3.3$ is specifically localized in gabaergic neurons of rodent thalamus and cerebral cortex. J Comp Neurol 519: 1181-1195, 2011.

Liu XB, Bolea S, Golshani P, Jones EG. Differentiation of corticothalamic and collateral thalamocortical synapse on mouse reticular nucleus neurons by EPSC amplitude and AMPA receptor subunit composition. Thalamus Related Syst 1: 15-29, 2001

Lozsádi DA. Organization of cortical afferents to the rostral, limbic sector of the rat thalamic reticular nucleus. J Comp Neurol 341: 520-533, 1994.

Lubke J. Morphology of neurons in the thalamic reticular nucleus (TRN) of mammals as revealed by intracellular injections into fixed brain slices. $J$ Comp Neurol 329: 458-471, 1993.

Meyer AH, Katona I, Blatow M, Rozov A, Monyer H. In vivo labeling of parvalbumin-positive interneurons and analysis of electrical coupling in identified neurons. J Neurosci 22: 7055-7064, 2002.

Moreno H, Burghardt NS, Vela-Duarte D, Masciotti J, Hua F, Fenton AA, Schwaller B, Small SA. The absence of the calcium-buffering protein calbindin is associated with faster age-related decline in hippocampal metabolism. Hippocampus 22: 1107-1120, 2012.

Park JY, Kang HW, Jeong SW, Lee JH. Multiple structural elements contribute to the slow kinetics of the Cav3.3 t-type channel. J Biol Chem 279: 21707-21713, 2004.

Paz JT, Bryant AS, Peng K, Fenno L, Yizhar O, Frankel WN, Deisseroth $\mathbf{K}$, Huguenard JR. A new mode of corticothalamic transmission revealed in the Gria4(-/-) model of absence epilepsy. Nat Neurosci 14: 1167-1173, 2011.

Perez-Reyes E. Molecular physiology of low-voltage-activated T-type calcium channels. Physiol Rev 83: 117-161, 2003.

Pinault D. Dysfunctional thalamus-related networks in schizophrenia. Schizophr Bull 37: 238-243, 2011.

Pinault D, Bourassa J, Deschênes M. The axonal arborization of single thalamic reticular neurons in the somatosensory thalamus of the rat. Eur $J$ Neurosci 7: 31-40, 1995.

Poulet JF, Fernandez LM, Crochet S, Petersen CC. Thalamic control of cortical states. Nat Neurosci 15: 370-372, 2012. 
R Core Team. R: A Language and Environment for Statistical Computing. Vienna, Austria: R Foundation for Statistical Computing, 2012.

Reynolds GP, Zhang ZJ, Beasley CL. Neurochemical correlates of cortical GABAergic deficits in schizophrenia: selective losses of calcium binding protein immunoreactivity. Brain Res Bull 55: 579-584, 2001.

Runyan CA, Schummers J, Van Wart A, Kuhlman SJ, Wilson NR, Huang ZJ, Sur M. Response features of parvalbumin-expressing interneurons suggest precise roles for subtypes of inhibition in visual cortex. Neuron 67: 847-857, 2010.

Sacerdote L, Villa AE, Zucca C. On the classification of experimental data modeled via a stochastic leaky integrate and fire model through boundary values. Bull Math Biol 68: 1257-1274, 2006

Scheibel ME, Scheibel AB. The organization of the nucleus reticularis thalami: a Golgi study. Brain Res 1: 43-62, 1966.

Schwaller B. The continuing disappearance of "pure" $\mathrm{Ca}^{2+}$ buffers. Cell Mol Life Sci 66: 275-300, 2009.

Schwaller B. The regulation of a cell's $\mathrm{Ca}^{2+}$ signaling toolkit: the $\mathrm{Ca}^{2+}$ homeostasome. Adv Exp Med Biol 740: 1-25, 2012.

Schwaller B, Dick J, Dhoot G, Carroll S, Vrbova G, Nicotera P, Pette D, Wyss A, Bluethmann H, Hunziker W, Celio MR. Prolonged contractionrelaxation cycle of fast-twitch muscles in parvalbumin knockout mice. $\mathrm{Am}$ J Physiol Cell Physiol 276: C395-C403, 1999.

Schwaller B, Tetko IV, Tandon P, Silveira DC, Vreugdenhil M, Henzi T, Potier MC, Celio MR, Villa AE. Parvalbumin deficiency affects network properties resulting in increased susceptibility to epileptic seizures. Mol Cell Neurosci 25: 650-663, 2004.

Servais L, Bearzatto B, Schwaller B, Dumont M, De Saedeleer C, Dan B, Barski JJ, Schiffmann SN, Cheron G. Mono- and dual-frequency fast cerebellar oscillation in mice lacking parvalbumin and/or calbindin D-28k. Eur J Neurosci 22: 861-870, 2005.

Servais L, Cheron G. Purkinje cell rhythmicity and synchronicity during modulation of fast cerebellar oscillation. Neuroscience 134: 1247-1259, 2005.

Sherman SM, Guillery RW. Distinct functions for direct and transthalamic corticocortical connections. J Neurophysiol 106: 1068-1077, 2011.

Shosaku A, Kayama Y, Sumitomo I. Somatotopic organization in the rat thalamic reticular nucleus. Brain Res 311: 57-63, 1984.

Sohal VS, Huguenard JR. Inhibitory interconnections control burst pattern and emergent network synchrony in reticular thalamus. J Neurosci 23: 8978-8988, 2003.

Spreafico R, Battaglia G, Frassoni C. The reticular thalamic nucleus (RTN) of the rat: cytoarchitectural, Golgi, immunocytochemical, and horseradish peroxidase study. J Comp Neurol 304: 478-490, 1991.

Steriade M, Deschenes M, Domich L, Mulle C. Abolition of spindle oscillations in thalamic neurons disconnected from nucleus reticularis thalami. J Neurophysiol 54: 1473-1497, 1985.
Steriade M, Domich L, Oakson G, Deschenes M. The deafferented reticular thalamic nucleus generates spindle rhythmicity. J Neurophysiol 57: 260273, 1987.

Steriade M, Parent A, Hada J. Thalamic projections of nucleus reticularis thalami of cat: a study using retrograde transport of horseradish peroxidase and fluorescent tracers. J Comp Neurol 229: 531-547, 1984.

Talley EM, Cribbs LL, Lee JH, Daud A, Perez-Reyes E, Bayliss DA. Differential distribution of three members of a gene family encoding low voltage-activated (t-type) calcium channels. J Neurosci 19: 1895-1911, 1999.

Teetor P. $R$ Cookbook (1st ed.). Sebastopol, CA: O'Reilly, 2011.

Theyel BB, Llano DA, Sherman SM. The corticothalamocortical circuit drives higher-order cortex in the mouse. Nat Neurosci 13: 84-88, 2010.

Toyota M, Ho C, Ohe-Toyota M, Baylin SB, Issa JP. Inactivation of cacna1g, a t-type calcium channel gene, by aberrant methylation of its $5^{\prime} \mathrm{cpg}$ island in human tumors. Cancer Res 59: 4535-4541, 1999.

Villa AE. Physiological differentiation within the auditory part of the thalamic reticular nucleus of the cat. Brain Res Rev 15: 25-40, 1990.

Villa AE, Bajo Lorenzana VM, Vantini G. Nerve growth factor modulates information processing in the auditory thalamus. Brain Res Bull 39: 139 147, 1996.

Villa AE, Tetko IV, Dutoit P, De Ribaupierre Y, De Ribaupierre F. Corticofugal modulation of functional connectivity within the auditory thalamus of rat, guinea pig and cat revealed by cooling deactivation. $J$ Neurosci Methods 86: 161-178, 1999.

Vreugdenhil M, Jefferys JG, Celio MR, Schwaller B. Parvalbumin-deficiency facilitates repetitive IPSCs and gamma oscillations in the hippocampus. J Neurophysiol 89: 1414-1422, 2003.

Wang XJ, Rinzel J. Spindle rhythmicity in the reticularis thalami nucleus: synchronization among mutually inhibitory neurons. Neuroscience 53: 899904, 1993.

Wills S, Rossi CC, Bennett J, Cerdeno VM, Ashwood P, Amaral DG, Van de Water J. Further characterization of autoantibodies to GABAergic neurons in the central nervous system produced by a subset of children with autism. Mol Autism 2: 5, 2011.

Yen CT, Conley M, Hendry SH, Jones EG. The morphology of physiologically identified gabaergic neurons in the somatic sensory part of the thalamic reticular nucleus in the cat. $J$ Neurosci 5: 2254-2268, 1985.

Yen CT, Shaw FZ. Reticular thalamic responses to nociceptive inputs in anesthetized rats. Brain Res 968: 179-191, 2003.

Yingling CD, Skinner JE. Selective regulation of thalamic sensory relay nuclei by nucleus reticularis thalami. Electroencephalogr Clin Neurophysiol 41: 476-482, 1976.

Zhang Y, Yoshida T, Katz DB, Lisman JE. NMDAR antagonist action in thalamus imposes delta oscillations on the hippocampus. J Neurophysiol 107: 3181-3189, 2012. 